\title{
G2019S-LRRK2 Expression Augments $\alpha$-Synuclein Sequestration into Inclusions in Neurons
}

\author{
ㄴoura A. Volpicelli-Daley, ${ }^{1}$ CHisham Abdelmotilib, ${ }^{1}$ Zhiyong Liu, ${ }^{1}$ Lindsay Stoyka, ${ }^{1}$ João Paulo Lima Daher, ${ }^{1}$ \\ (ํ)Austen J. Milnerwood, ${ }^{2}$ Vivek K. Unni, ${ }^{3}$ Warren D. Hirst, ${ }^{4}$ Zhenyu Yue, ${ }^{5}$ Hien T. Zhao, ${ }^{6}$ OKyle Fraser, ${ }^{1}$ \\ - Richard E. Kennedy, ${ }^{7}$ and Andrew B. West ${ }^{1}$ \\ ${ }^{1}$ Center for Neurodegeneration and Experimental Therapeutics, Department of Neurology, University of Alabama at Birmingham, Birmingham, Alabama \\ 35294, ${ }^{2}$ Centre for Applied Neurogenetics, Medical Genetics, University of British Columbia, Vancouver, British Columbia, V6T 1Z3 Canada, ${ }^{3}$ Jungers \\ Center for Neurosciences Research and Parkinson Center of Oregon, Department of Neurology, Oregon Health \& Science University, Portland, Oregon \\ 97239, 4Pfizer Neuroscience and Pain Research Unit, Cambridge, Massachusetts 02139, ${ }^{5}$ Departments of Neurology and Neuroscience, Friedman Brain \\ Institute, Icahn School of Medicine at Mount Sinai, New York, New York 10029, ${ }^{6}$ Ionis Pharmaceuticals, Carlsbad, California 92010, and ${ }^{7}$ Comprehensive \\ Center for Healthy Aging and Division of Gerontology, Geriatrics, and Palliative Care, Department of Medicine, University of Alabama at Birmingham, \\ Birmingham, Alabama 35294
}

Pathologic inclusions define $\alpha$-synucleinopathies that include Parkinson's disease (PD). The most common genetic cause of PD is the G2019S LRRK2 mutation that upregulates LRRK2 kinase activity. However, the interaction between $\alpha$-synuclein, LRRK2, and the formation of $\alpha$-synuclein inclusions remains unclear. Here, we show that G2019S-LRRK2 expression, in both cultured neurons and dopaminergic neurons in the rat substantia nigra pars compact, increases the recruitment of endogenous $\alpha$-synuclein into inclusions in response to $\alpha$-synuclein fibril exposure. This results from the expression of mutant G2019S-LRRK2, as overexpression of WT-LRRK2 not only does not increase formation of inclusions but reduces their abundance. In addition, treatment of primary mouse neurons with LRRK2 kinase inhibitors, PF-06447475 and MLi-2, blocks G2019S-LRRK2 effects, suggesting that the G2019S-LRRK2 potentiation of inclusion formation depends on its kinase activity. Overexpression of G2019S-LRRK2 slightly increases, whereas WT-LRRK2 decreases, total levels of $\alpha$-synuclein. Knockdown of total $\alpha$-synuclein with potent antisense oligonucleotides substantially reduces inclusion formation in G2019S-LRRK2-expressing neurons, suggesting that LRRK2 influences $\alpha$-synuclein inclusion formation by altering $\alpha$-synuclein levels. These findings support the hypothesis that G2019S-LRRK2 may increase the progression of pathological $\alpha$-synuclein inclusions after the initial formation of $\alpha$-synuclein pathology by increasing a pool of $\alpha$-synuclein that is more susceptible to forming inclusions.

Key words: Lewy body; Lewy neurite; LRRK2; Parkinson's; synuclein

\section{Significance Statement}

$\alpha$-Synuclein inclusions are found in the brains of patients with many different neurodegenerative diseases. Point mutation, duplication, or triplication of the $\alpha$-synuclein gene can all cause Parkinson's disease (PD). The G2019S mutation in LRRK2 is the most common known genetic cause of PD. The interaction between G2019S-LRRK2 and $\alpha$-synuclein may uncover new mechanisms and targets for neuroprotection. Here, we show that expression of G2019S-LRRK2 increases $\alpha$-synuclein mobility and enhances aggregation of $\alpha$-synuclein in primary cultured neurons and in dopaminergic neurons of the substantia nigra pars compacta, a susceptible brain region in PD. Potent LRRK2 kinase inhibitors, which are being developed for clinical use, block the increased $\alpha$-synuclein aggregation in G2019S-LRRK2-expressing neurons. These results demonstrate that $\alpha$-synuclein inclusion formation in neurons can be blocked and that novel therapeutic compounds targeting this process by inhibiting LRRK2 kinase activity may slow progression of PD-associated pathology.

\section{Introduction}

$\alpha$-Synuclein plays a central role in the development of Parkinson's disease (PD), dementia with Lewy bodies, multiple system atrophy, and is associated with Alzheimer's disease and other neurodegenerative disorders. This is based on evidence that the inclusions that form in the brain, such as Lewy bodies and Lewy neuritis, are composed of $\alpha$-synuclein (Duda et al., 2000; Spillantini and Goedert, 2000). In addition, autosomal dominant missense mutations in SNCA (encoding $\alpha$-synuclein), as well as multiplication of the number of wild-type SNCA alleles that increase protein expression can cause PD (Singleton et al., 2003; Chartier-Harlin et al., 2004; Ibáñez et al., 2004). The mechanism 
by which $\alpha$-synuclein converts from its physiologic to pathologic form remains to be fully understood. Recent findings suggest that stressors and/or PD-linked mutations may promote a shift in $\alpha$-synuclein protein from an oligomeric membrane-associated form to a soluble monomeric form prone to misfolding and aggregation (Burré et al., 2015; Dettmer et al., 2015a, 2016).

Missense mutations in the LRRK2 gene are the most common known cause of PD and may facilitate pathological processes underlying $\alpha$-synuclein neurotoxicity. Mice coexpressing LRRK2 with the pathogenic G2019S mutation and $\alpha$-synuclein with the pathogenic A53T mutation show increased neurodegeneration and increased $\alpha$-synuclein aggregate formation (Lin et al., 2009; Daher et al., 2012). In addition, death of substantia nigra dopaminergic neurons induced by viral overexpression of $\alpha$-synuclein is exacerbated in rats expressing G2019S-LRRK2 (Daher et al., 2015). Although mice overexpressing mutant $\alpha$-synuclein either through transgenes or viral transduction provide a valuable tool for understanding the impact of abnormal $\alpha$-synuclein in vivo, $\alpha$-synuclein aggregation is often coincident with cell death and/or mortality; thus, the progression of inclusion formation over time is difficult to analyze with conventional staining techniques (Giasson et al., 2002; Lee et al., 2002), although newer in vivo imaging approaches may be able to provide some insight (Osterberg et al., 2015).

Recently, we described a model in which preformed fibrils of $\alpha$-synuclein applied in low concentrations (nanomolar) in vitro or in vivo to neurons cause the formation of ubiquitinated and phosphorylated $\alpha$-synuclein inclusions with morphological characteristics that overlap with those found in postmortem PD brain (Volpicelli-Daley et al., 2011, 2014b; Luk et al., 2012). These inclusions are formed from endogenously expressed $\alpha$-synuclein as neurons from $\alpha$-synuclein knock-out mice cannot form these inclusions (Volpicelli-Daley et al., 2011). Here, we examine the effects of G2019S-LRRK2 expression in neurons on the formation of $\alpha$-synuclein pathology both in cultured neurons and in vivo. Our results suggest that G2019S-LRRK2 may enhance the development of $\alpha$-synuclein pathology over time, potentially explaining a new link between the G2019S LRRK2 mutation and PD susceptibility.

\section{Materials and Methods}

Animals. All animal protocols were approved by the University of Alabama at Birmingham's Institutional Animal Care and Use Committee and were in accordance with the National Institute of Health Guide for the Care and Use of Laboratory Animals (Publication No. 80-23). The murine G2019S-LRRK2 and WT-LRRK2 BAC mice were previously described (Li et al., 2010) and have been backcrossed onto the C57BL/6J mice for $>10$ generations. The Sprague Dawley human G2019S-LRRK2

Received Oct. 2, 2015; revised May 23, 2016; accepted May 26, 2016.

Author contributions: L.A.V.-D., Z.L., L.S., H.T.Z., and A.B.W. designed research; L.A.V.-D., H.A., Z.L., L.S., J.P.L.D. and K.F. performed research; L.A.V.-D., W.D.H., Z.Y., and H.T.Z. contributed unpublished reagents/analytic tools; L.A.V.-D., H.A., L.S., A.J.M., V.K.U., W.D.H., Z.Y., K.F., R.E.K., and A.B.W. analyzed data; L.A.V.-D., Z.L., and A.B.W. wrote the paper.

This work was supported by American Parkinson's Disease Association Grant to L.A.V.-D., Michael J. Fox Foundation LEAPS Award to A.B.W, L.A.V.-D., and W.D.H., and National Institutes of Health Grant R01 NS064934 to A.B.W. We thank Valentina Krendelshchikova and Mark Moehle for assistance with protein purification; and David Standaert for helpful discussions.

W.D.H. was an employee of Pfizer and H.T.Z. was an employee of lonis Pharmaceuticals during the period when the data were generated and interpreted. The remaining authors declare no competing financial interests.

Correspondence should be addressed to Dr. Laura A. Volpicelli-Daley, University of Alabama at Birmingham, Center for Neurodegeneration and Experimental Therapeutics, 1719 6th Avenue South, Birmingham, AL 35294. E-mail: volpicel@uab.edu.

W. D. Hirst's present address: Neurology Research, Biogen, Cambridge, Massachusetts 02142.

DOI:10.1523/JNEUROSCI.3642-15.2016

Copyright $\odot 2016$ the authors $\quad 0270-6474 / 16 / 367416-13 \$ 15.00 / 0$
BAC transgenic rats were developed in the laboratory of Chenjian $\mathrm{Li}$, rederived at Taconic Farms, and have been previously characterized (West et al., 2014). Both female and male rodents were used in this study.

Primary neuron cultures. Primary neuron cultures were prepared as described previously (Volpicelli-Daley et al., 2014a). Briefly, the hippocampi were dissected from the brains of embryonic (E16-E17) mice in Hibernate E (BrainBits), digested with papain (Worthington Biochemical) in HBSS supplemented with HEPES (10 mM) and sodium pyruvate (1 $\mathrm{mm}$ ) and $1 \%$ penicillin/streptomycin (pen/strep), triturated and plated in Neurobasal Media (Invitrogen) with B27 (Invitrogen), GlutaMAX (Invitrogen), and 10\% FBS. Two to $24 \mathrm{~h}$ later, the media was completely exchanged Neurobasal/B27/GlutaMAX (no pen/strep). Neurons were plated onto poly-D-lysine-coated coverslips or wells at $5 \times 10^{4}$ cells per $\mathrm{cm}^{2}$.

Transfections. At day in vitro (DIV) 5 or 6, neurons for some experiments were transfected with plasmids encoding human synuclein-eGFP (Volpicelli-Daley et al., 2014b) using lipofectamine LTX (Invitrogen). For each MatTek dish with $2 \mathrm{ml}$ of neuronal media, $1 \mathrm{ml}$ was removed and saved as conditioned media. For the transfection, $1 \mu \mathrm{l}$ of Lipofectamine LTX was incubated in prewarmed $50 \mu \mathrm{l}$ of DMEM and combined with $50 \mu \mathrm{l}$ of DMEM with $1 \mu \mathrm{g}$ of plasmid DNA and $1 \mu \mathrm{l}$ of Lipofectamine PLUS reagent at a final volume of $100 \mu \mathrm{l}$, and incubated for $5 \mathrm{~min}$. The mixture was added to $1 \mathrm{ml}$ neuronal media in the dish (without pen/strep); and $4 \mathrm{~h}$ later, the media was completely exchanged with neuronal media (50/50 mix of fresh media and conditioned media).

Preparation of fibrils and addition to primary neuron cultures. Mouse $\alpha$-synuclein was expressed in Escherichia coli and purified as described previously (Volpicelli-Daley et al., 2011, 2014a). To generate fibrils, 5 $\mathrm{mg} / \mathrm{ml}$ of purified $\alpha$-synuclein in $50 \mathrm{~mm}$ Tris-HCl, pH 7.5, $150 \mathrm{~mm} \mathrm{KCL}$ ("buffer A" from Bousset et al., 2013) was shaken at $1000 \mathrm{rpm}$ in a thermomixer for $7 \mathrm{~d}$. On the day the fibrils were added to neurons (DIV 7), the fibrils were thawed, diluted in PBS to $100 \mu \mathrm{g} / \mathrm{ml}$, and sonicated using a $1 / 8$ inch probe tip (Fisher Scientific, model 120, catalog \#FB120110) for $30 \mathrm{~s}$ total time with $1 \mathrm{~s}$ on and $1 \mathrm{~s}$ off at $10 \%$ power. Neurons were exposed to $2 \mu \mathrm{g} / \mathrm{ml}$ of fibrils. Sedimentation assays and thioflavin $\mathrm{T}$ assays were performed as described previously (VolpicelliDaley et al., 2014a) to ensure fibril quality. The Pierce LAL endotoxin detection kit determined that $0.004 \mathrm{ng} / \mathrm{ml}$ of endotoxin was added to the primary cultures.

Antisense oligonucletides. The antisense oligonucleotides (ASOs) were synthesized and provided by Ionis Pharmaceuticals (Bennett and Swayze, 2010). The sequence of the $\alpha$-synuclein ASO was TTTAATT ACTTCCACCA, and the sequence of the control ASO was CCTATAG GACTATCCAGGAA.

Immunoblotting. Neurons were scraped into cold 1\% Triton X-100 in 50 mм Tris, 150 mм NaCl, pH 7.4 (TBS) with PhosSTOP phosphatase inhibitors and Complete protease inhibitor mixture (Roche Life Science), sonicated and centrifuged at $20,000 \times g$ at $4^{\circ} \mathrm{C}$. The supernatant was added to $2 \times$ Laemmli buffer with 5\% DTT, 40 mm sodium fluoride, and equal concentrations of protein were subjected to SDS-PAGE using 7.5\% TGX gels for LRRK2 immunoblots and 4\%-20\% gradient gels (Bio-Rad) for synuclein immunoblots and transferred to PVDF (Millipore Immobilon P). Blots were blocked in TBS, 0.1\% Tween 20 and $5 \%$ skimmed-milk. Primary antibodies were diluted in blocking buffer. Primary antibodies included the following: synuclein mouse antibody (Syn1, BD Biosciences), LRRK2 (c41-2; Abcam), pS1292-LRRK2 (MJFR-19-7-8, Abcam), VDAC (NeuroMab), and Tuj1 (Neuromics Antibodies). Following washing, membranes were incubated in HRPconjugated secondary antibodies (Jackson ImmunoResearch Laboratories), washed and developed using enhanced chemiluminescence. Immunoblots were quantified using ImageJ.

Immunofluorescence, and quantitation of images. Primary neurons were fixed with $4 \%$ PFA and $4 \%$ sucrose in PBS, pH 7.4. Neurons were blocked and permeabilized with $3 \%$ BSA and $0.1 \%$ Triton X-100. Following rinsing, neurons were incubated in primary antibody diluted in PBS and 3\% BSA as previously described (Volpicelli-Daley et al., 2011, 2014a). Primary antibodies included mAB81A (Waxman and Giasson, 2008), MAP2 (Fisher Scientific), and tau (Dako). Following rinses, neurons were incubated in secondary antibodies diluted in PBS and 3\% 
BSA. Secondary antibodies were AlexaFluor-conjugated anti-rabbit, anti-mouse whole IgG, anti-mouse IgG1-specific, or anti-mouse IgG2aspecific (Invitrogen). After rinsing, coverslips were mounted using Prolong Gold mounting media (Invitrogen). Immunofluorescent images were captured using a Leica TCS-SP5 laser scanning confocal microscope using computer-assisted image acquisition and an automated stage. All images were captured at the same laser power, gain, and offset. For each experiment, at least 10 images were acquired in a randomly assigned grid on each coverslip, and all experiments were repeated at least three times using independent cultures from different breeding pairs of mice. Images were quantified using ImageJ as previously described (Tran et al., 2014). The MaxEntropy Autothreshold function was applied to each image. The percentage area occupied was quantified using the Measure function.

Fluorescence recovery after photobleaching (FRAP). Neurons were imaged $18 \mathrm{~d}$ after adding fibrils (DIV 21-25). FRAP was performed using a Nikon A1 High Speed Laser Confocal Spectral Imaging microscope with a $63 \times$ oil-immersion objective at the UAB High Resolution Imaging Shared Facility. Imaging was performed using Tyrode's buffer $(136 \mathrm{~mm}$ $\mathrm{NaCl}, 2.5 \mathrm{~mm} \mathrm{KCl}, 2 \mathrm{mM} \mathrm{CaCl}_{2}, 1.3 \mathrm{~mm} \mathrm{MgCl}_{2}, 10 \mathrm{~mm}$ glucose, and $10 \mathrm{~mm}$ HEPES). $\alpha$-Synuclein puncta that were an average length of $\leq 2.0 \mu \mathrm{m}$ were identified and bleached using a $405 \mathrm{~nm}$ laser (longer serpentine $\alpha$-synuclein-GFP in the fibril-treated cultures were not included in the analyses). After bleaching, images were captured every $233 \mathrm{~ms}$ for a remaining $30 \mathrm{~s}$. The fluorescence intensity was quantified using the Nikon software. The average prebleach intensity was calculated, and the percentage recovery after photobleaching was calculated as the ratio of the increase in fluorescence intensity from $t=0 \mathrm{~s}$ to $t=30 \mathrm{~s}$ divided by the total bleached amount.

Surgeries. Hemizygous rats carrying the human G2019S-LRRK2 BAC transgene, identified by PCR with DNA derived from tail snips using primers GAT AGG CGG CTT TCA TTT TTC C and ACT CAG GCC CCA AAA ACG AG, together with Phusion TaqDNA polymerase (New England Biolabs). Transmission of the BAC transgene was 50\%, and littermates not positive for the transgene were included in the experiments as nontransgenic (nonTg). Both males and female rats were included in the experiments, and no gender effects could be observed in this study. At 10-12 weeks of age, rats were deeply anesthetized with isofluorane and stereotactically injected with $4 \mu \mathrm{l}$ of $5 \mathrm{mg} / \mathrm{ml}$ of sonicated fibrils into the right substantia nigra pars compacta (SNpc) or $4 \mu \mathrm{l}$ of 5 $\mathrm{mg} / \mathrm{ml}$ monomeric $\alpha$-synuclein into the left SNpc. Coordinates were 4.65 $\mathrm{mm}$ posterior, $2.25 \mathrm{~mm}$ lateral to bregma, and $4.45 \mathrm{~mm}$ ventral.

Immunohistochemistry and immunofluorescence in rat brain sections. Four weeks after injections, rats were anesthetized with isoflurane and transcardially perfused with $0.9 \%$ saline and 10 units $/ \mathrm{ml}$ heparin followed by ice-cold $4 \%$ PFA in PBS. Brains were dissected, postfixed in $4 \%$ PFA for $2 \mathrm{~h}$ at $4^{\circ} \mathrm{C}$, cryoprotected with $30 \%$ sucrose in PBS, and flash frozen in isopentane and stored at $-80^{\circ} \mathrm{C}$. The $40 \mu \mathrm{m}$ coronal sections were obtained using a freezing microtome. Sections were rinsed several times with TBS. Sections were incubated for $10 \mathrm{~min}$ in $3 \% \mathrm{H}_{2} \mathrm{O}_{2}$, rinsed, incubated in $10 \mathrm{~mm}$ sodium citrate, $\mathrm{pH} 6.0,0.05 \%$ Tween 20 , for $30 \mathrm{~min}$ at $37^{\circ} \mathrm{C}$. Sections were blocked and permeabilized with $5 \%$ normal goat or donkey serum, $0.3 \%$ concentration, in $0.3 \%$ Triton X-100, TBS, rinsed and incubated in primary antibody in 5\% normal serum TBS for $24-48$ $\mathrm{h}$ at $4^{\circ} \mathrm{C}$ with agitation. Primary antibodies included mAB81A (Waxman and Giasson, 2008), TH (Santa Cruz Biotechnology), and NeuN (Millipore). After rinsing, sections were incubated in secondary antibody in $5 \%$ normal serum and TBS overnight at $4^{\circ} \mathrm{C}$ with agitation. After rinses, sections were processed for immunofluorescence and mounted onto charged slides using Prolong Gold (Invitrogen). For DAB staining, sections were incubated with Avidin-Biotin Complex reagent (Vector Laboratories) for $30 \mathrm{~min}$, rinsed and developed in ImmPACT-DAB (Vector Laboratories). Sections were counterstained with $0.1 \% \mathrm{mg} / \mathrm{ml}$ cresyl violet rinsed, dehydrated, and mounted with Permount (ThermoFisher). Immunofluorescent images were captured using a Leica TCS-SP5 laser scanning confocal microscope. Images of DAB-stained sections were captured using an Olympus BX61 microscope. Images were processed using Adobe Photoshop for contrast and brightness and arranged in Adobe Illustrator.
Stereology. Unbiased sterological estimations of TH and Nissl-positive cells in the SNpc were performed by investigators blinded to genotype and experimental conditions. Contours of the SNpc were identified by Nissl stain using a low-power objective. Sections covered the entire SNpc and were equally spaced $120 \mu \mathrm{m}$ apart, with the Optical Fractionator probe placed randomly, as performed previously (Daher et al., 2014). All estimations were based on counts from at least 150 objects in the randomly assigned grids. Unbiased stereological estimation of total number of pS129- $\alpha$-synuclein-positive perikaryal inclusions in the SNpc was also performed by an investigator blinded to experimental conditions using the rare-event counting probe in a Stereologer System (Stereology Resource Center). Animals were rejected from the analysis, as noted in figure legends, if an observer blinded to the experimental conditions determined that the injection site was not in the SNpc.

Kinase assays. A total of $10 \mathrm{~nm}$ of recombinant GST-tagged human LRRK2 ( $\Delta 970-2527$, Invitrogen) was incubated with $10 \mu \mathrm{M}$ LRRKtide (Thermo Fisher), $100 \mu \mathrm{M}$ ATP, and $0.1 \mu \mathrm{Ci}\left[\gamma_{-}{ }^{32} \mathrm{P}\right] \mathrm{ATP}$ in buffer containing $150 \mathrm{~mm}$ $\mathrm{NaCl}, 5 \mathrm{~mm} \mathrm{MgCl} 2,50 \mathrm{~mm}$ Tris, pH 7.5. MLi-2 or PF-06447475, synthesized in-house, was titrated into the kinase reactions at $0-1000 \mathrm{~nm}$ concentration as indicated. Kinase reactions were stopped by heating at $90^{\circ} \mathrm{C}$ after $1 \mathrm{~h}$ incubation at $30^{\circ} \mathrm{C}$ followed by loading kinase reactions to P81 filter paper (GE Healthcare). P81 paper was washed three times with 5\% phosphoric acid followed by liquid scintillation counting. To determine the ATPcompetitiveness of the LRRK2 kinase inhibitors, $1.1 \mathrm{~nm}$ Mli2 or $3.5 \mathrm{~nm}$ PF06447475 (half-maximal inhibitory concentrations, respectively) were incubated with $10 \mathrm{~nm}$ recombinant GST-LRRK2 and $10 \mu \mathrm{M}$ LRRKtide, in the presence of $0-2 \mathrm{~mm} \gamma{ }^{-32} \mathrm{P}$ labeled ATP $(1 \mu \mathrm{Ci}$ added per $1 \mathrm{~mm}$ ATP). All data points were calculated from at least three independent reactions. The amount of phosphate incorporated into LRRKtide was determined by liquid scintillation counting. $K_{\mathrm{m}}$ and $V_{\max }$ values were determined using GraphPad Prism 5.0.

Statistical analyses. The area occupied by $\mathrm{p}-\alpha$-synuclein was estimated using mixed-effects models (covariance pattern models) to test for differences among groups. The mixed-effects model was used as it better controls for Type I errors in the presence of missing data. Because the area occupied by $\mathrm{p}-\alpha$-synuclein did not fit a normal distribution, a square root transformation was used to normalize values for the area before analysis. To account for the correlation among the fields within an experiment, fields were modeled as a random effect, nested within the experiment. An exchangeable correlation structure was used to model the correlation among fields. Parameters were estimated using restricted maximum likelihood, with $p$ values calculated using a Satterthwaite approximation. All calculations were performed using the lme4 package,3 version 1.1-11, in the R statistical computing environment, 4 version 3.3.0.

For the fluorescence recovery after photobleaching experiments, rates of recovery of fluorescence were similarly estimated using mixed-effects linear models (random coefficients models) to test for differences in slopes (rates of change) between two groups. The data were best fit by a linear and quadratic combined model. A full model was constructed with group and time effects and group $\times$ time interactions, and a reduced model with only time and group effects. A diagonal covariance matrix was used to model the correlation of slope and intercept parameters. Parameters were estimated using maximum likelihood, with CIs calculated from the likelihood profile using the likelihood ratio test. All calculations were performed using the glmmADMB package, 5 version 0.8 .3 .2 , in $\mathrm{R}$.

\section{Results}

Increased $\alpha$-synuclein in G2019S-LRRK2-expressing neurons To study the effects of G2019S-LRRK2 on $\alpha$-synuclein inclusions, we selected WT-LRRK2 and G2019S-LRRK2 BAC strains congenic on C57BL/6J that express protein at equivalent levels and consistent with the distribution of endogenous LRRK2 protein in the mouse brain (Li et al., 2010; Webber et al., 2011; West et al., 2014). We first characterized the levels of WT-LRRK2 and G2019S-LRRK2 in neurons compared with nonTg mice in cultured hippocampal neurons. LRRK2 levels were analyzed by immunoblot from lysates extracted at DIV 21, when neurons are mature (Fletcher et al., 1994). Levels of LRRK2 were 10- to 12- 
A

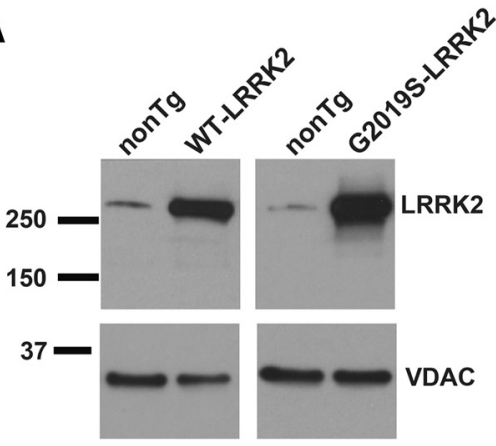

B

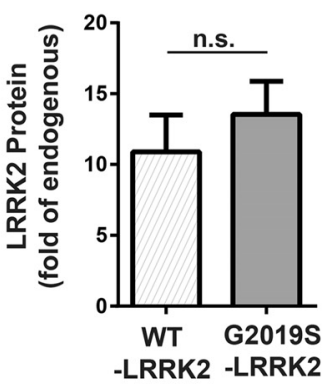

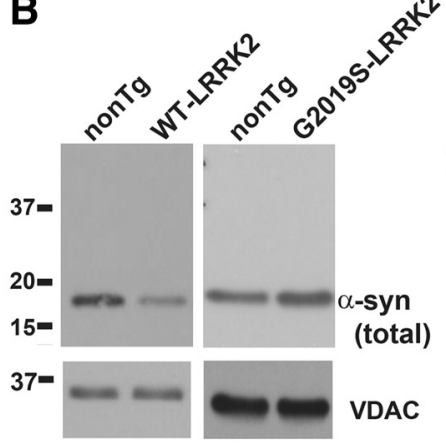

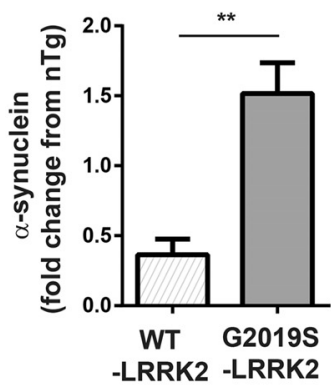

C
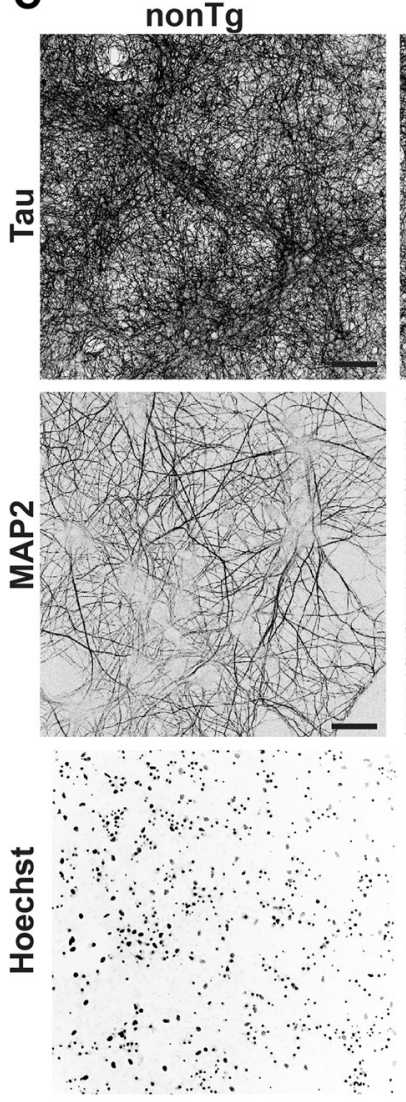

WT-LRRK2
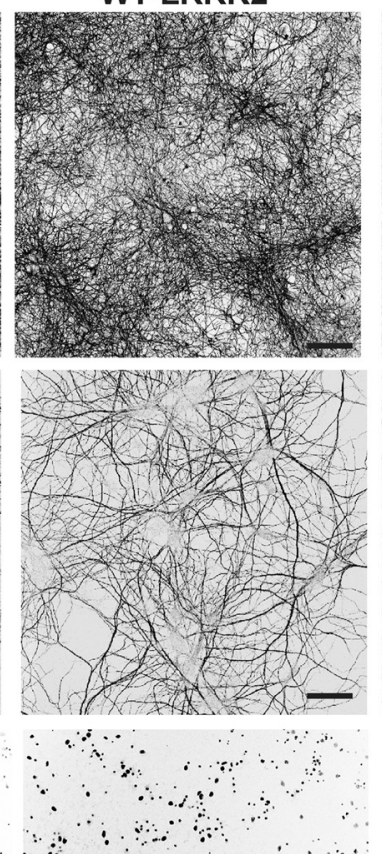

G2019S-LRRK2
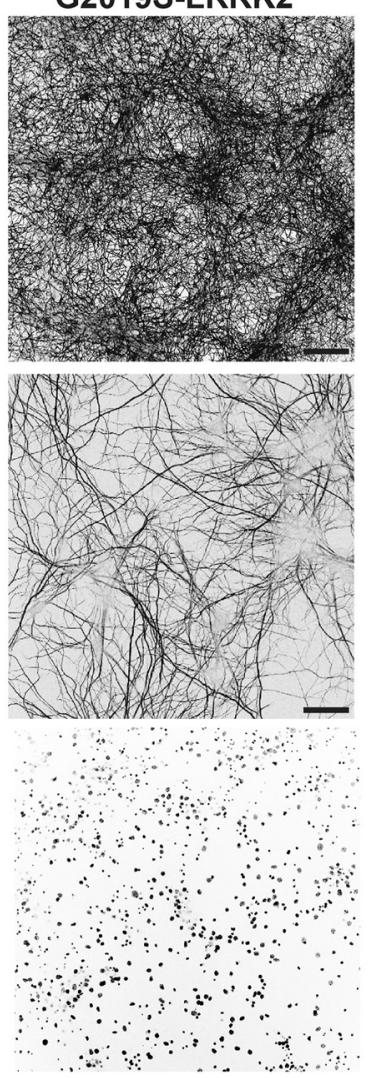

D

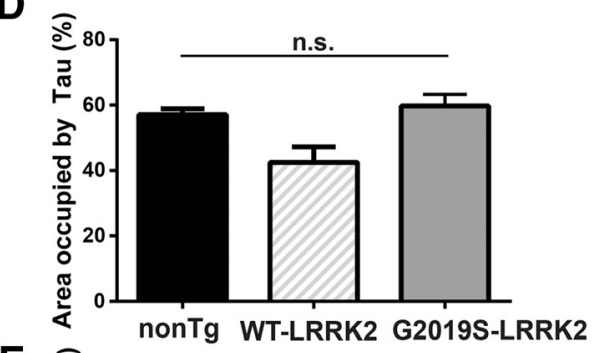

E

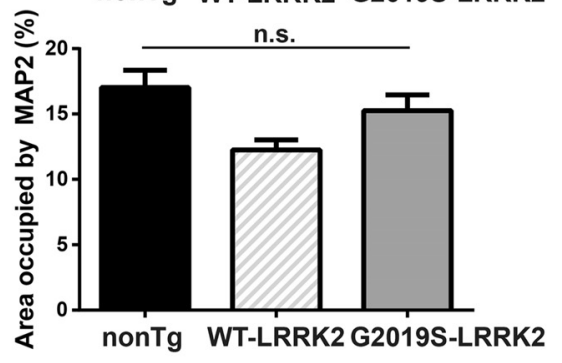

$F$

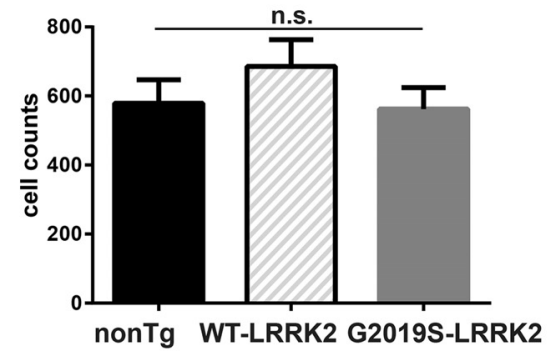

Figure 1. G2019S-LRRK2 expression increases $\alpha$-synuclein expression in primary neurons. $\boldsymbol{A}$, Representative immunoblots of lysates for total LRRK2 expression or (B) $\alpha$-synuclein from DIV 21 primary hippocampal neurons cultured from WT-LRRK2 BAC, G2019S-LRRK2 BAC, or from nonTg mice. Equivalent protein concentrations ( $\sim 10 \mu \mathrm{g})$ were loaded per lane. Quantification of immunoblots are from $N=11$ pairs of G2019S-LRRK2 and nonTg cultures from independent breeders and $N=4$ pairs of WT-LRRK2 and nonTg cultures. ${ }^{* *} p<0.001$. n.S., Not significant. $C$, Representative confocal micrographs of hippocampal neurons (DIV 21) stained with antibodies to tau, MAP2, or stained with Hoechst, as indicated. D, Quantification is shown for the area occupied by tau (for each genotype, $N=20,10$ images each from 2 independent experiments), $(\boldsymbol{E})$ MAP2 (for each genotype, $N=20,10$ images each from 2 independent experiments), or $(\boldsymbol{F})$ total counts of Hoechst nuclei (nonTg: $N=52$ images from 5 independent experiments; WT-LRRK2: $N=65$ images from 5 independent experiments; G2019S-LRRK2: $N=55$ images from 5 independent experiments). Scale bars, $100 \mu \mathrm{m}$. Bar charts represent group mean. Error bars indicate SEM.

fold increased in neurons from WT-LRRK2 and G2019S-LRRK2 BAC transgenic mice relative to nonTg neurons (Fig. 1A). Unexpectedly, levels of Triton X-100 extracted $\alpha$-synuclein were decreased by half in neurons from WT-LRRK2-overexpressing mice and increased approximately 1.5-fold in neurons from G2019S$L R R K 2$-expressing mice, compared with nonTg control neurons (Fig. 1B).

The efficiency of fibrils to induce inclusions depends on the maturation stage and density of neurons (Volpicelli-Daley et al., $2014 a, b)$. Inclusion formation also depends on $\alpha$-synuclein expression in synapses and synaptic maturation (Murphy et al., 2000). However, expression of G2019S-LRRK2 has been shown to negatively regulate neurite growth (MacLeod et al., 2006; Dächsel et al., 2010), at least before the neurons are fully mature. To understand whether increased expression of WT or G2019SLRRK2 affected the abundance of neurites in cultured neurons, we analyzed tau-positive axons and MAP2-positive dendrites using immunofluorescence and confocal microscopy (Fig. 1C). There were no overt morphological differences between the WT-LRRK2, G2019S-LRRK2, or nonTg control neurons, and quantitation of confocal images revealed no significant difference in the abundance of axons, dendrites, or total cell numbers in culture (Fig. $1 D-F$ ). These data are consistent with previous findings from this strain of mice that show expression of G2019S- 


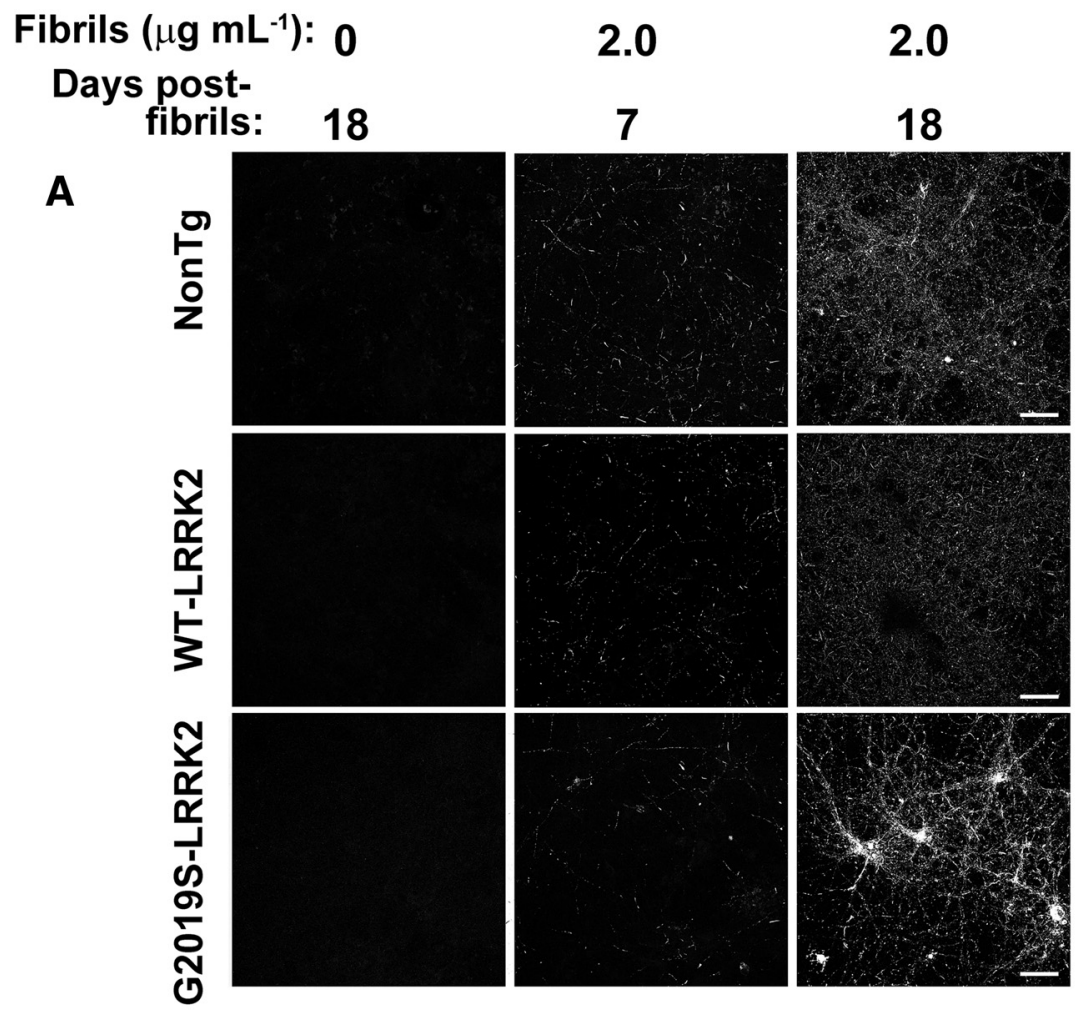

B
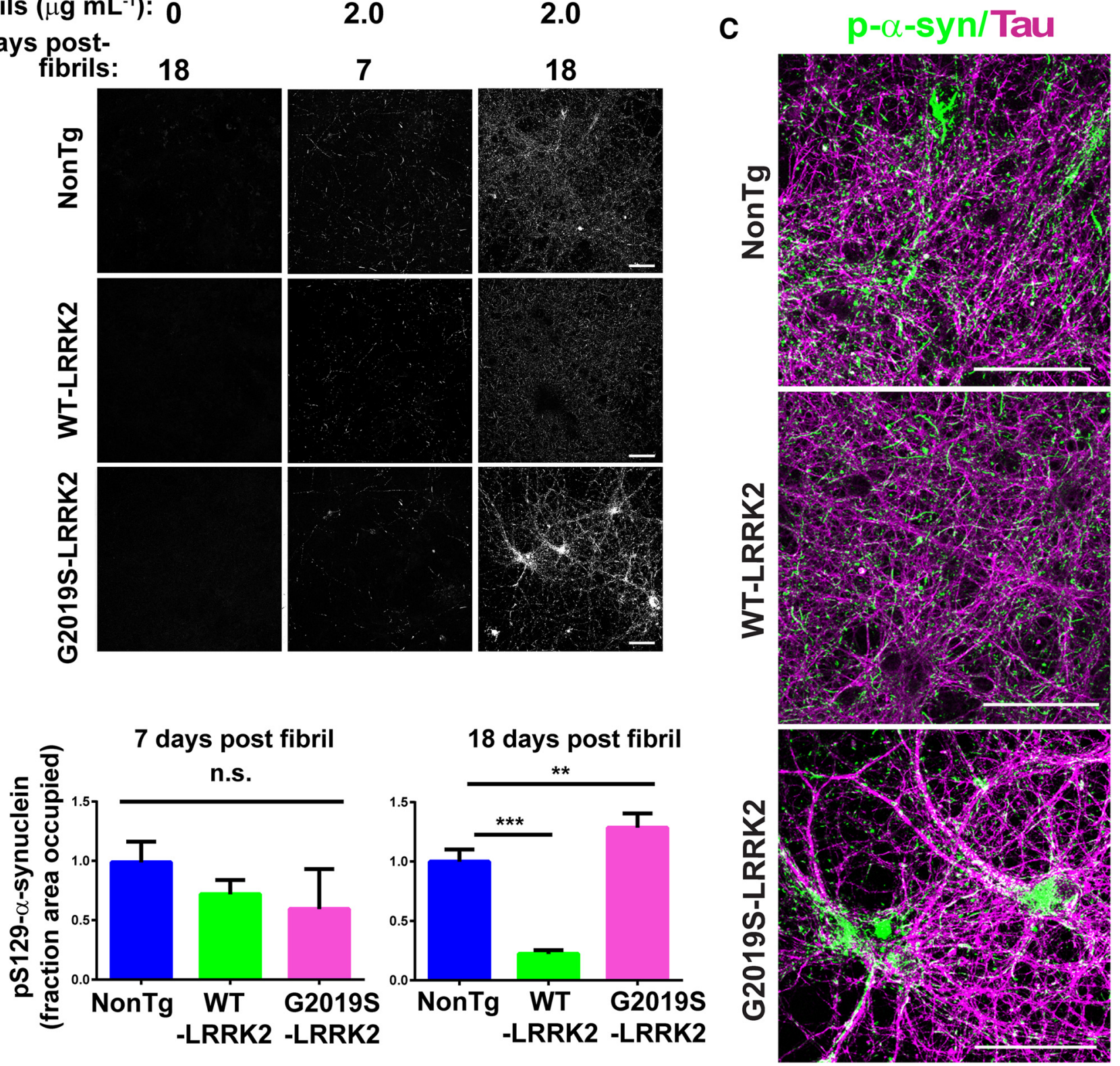

Figure 2. G2019S-LRRK2 expression exacerbates fibril-induced pS129- $\alpha$-synuclein inclusions in primary neurons. $A$, Representative confocal images of pS129- $\alpha$-synuclein staining in primary hippocampal neurons from nonTg, WT-LRRK2 BAC, or G2019S-BAC mice plated at equivalent densities. B, Quantification of pS129- $\alpha$-synuclein signal 7 or $18 \mathrm{~d}$ after the addition of $2.0 \mu \mathrm{g} / \mathrm{ml}$ of sonicated fibrils. For $7 \mathrm{~d}$ after fibrils, for each genotype, $N=20$ images from 2 independent experiments. For $18 \mathrm{~d}$ after fibrils nonTg: $N=70$ from 5 independent experiments; WT-LRRK2: $N=60$ from 4 independent experiments; G2019S-LRRK2: $N=70$ from 5 independent experiments. ${ }^{* *} p=0.002 .{ }^{* * *} p<0.001$. Bars represent group mean calculated. Error bars indicate SEM. $C$, Representative confocal images of primary neurons from nonTg, WT-LRRK2 BAC, and G2019S-LRRK2 BAC mice treated at DIV 7 with $2.0 \mu \mathrm{g} / \mathrm{ml}$ fibrils and analyzed for pS129- $\alpha$-synuclein (green) and tau (magenta) $18 \mathrm{~d}$ later. Scale bars, $100 \mu$ m. n.s., Not significant.

LRRK2 has no effect on axon or dendritic development after DIV 7 (Sepulveda et al., 2013).

G2019S-LRRK2 enhances the abundance of $\alpha$-synuclein inclusions

To test whether neurons expressing G2019S-LRRK2 are more sensitive to forming pathologic $\alpha$-synuclein inclusions, sonicated $\alpha$-synuclein fibrils were added to neurons from nonTg mice, WT-LRRK2 mice, or G2019S-LRRK2 BAC transgenic mice at DIV 7 , and at either 7 or $18 \mathrm{~d}$ after adding sonicated fibrils, neurons were fixed and immunofluorescence was performed using an antibody to pS129- $\alpha$-synuclein, a marker of inclusion formation (Fig. 2A) (Waxman and Giasson, 2008). In neurons not exposed to fibrils, there was minimal pS129- $\alpha$-synuclein immunofluorescence. Following $7 \mathrm{~d}$ incubation with sonicated fibrils, the pS129- $\alpha$-synuclein immunofluorescence in both neurons from nonTg mice, WT-LRRK2 mice, and G2019S-LRRK2 mice was much more intense with punctate and serpentine inclusions. Confocal analysis for pS129- $\alpha$-synuclein immunofluorescence intensity $7 \mathrm{~d}$ after fibril exposure demonstrated that there were no differences in the abundance of $\alpha$-synuclein inclusions in neurons from G2019S-LRRK2 mice compared with control nonTg neurons (Fig. 2B)

Eighteen days after exposure to $2 \mu \mathrm{g} / \mathrm{ml}$ of sonicated fibrils, there was a significant increase in the abundance of inclusions in the G2019S-LRRK2-expressing neurons compared with control 
A

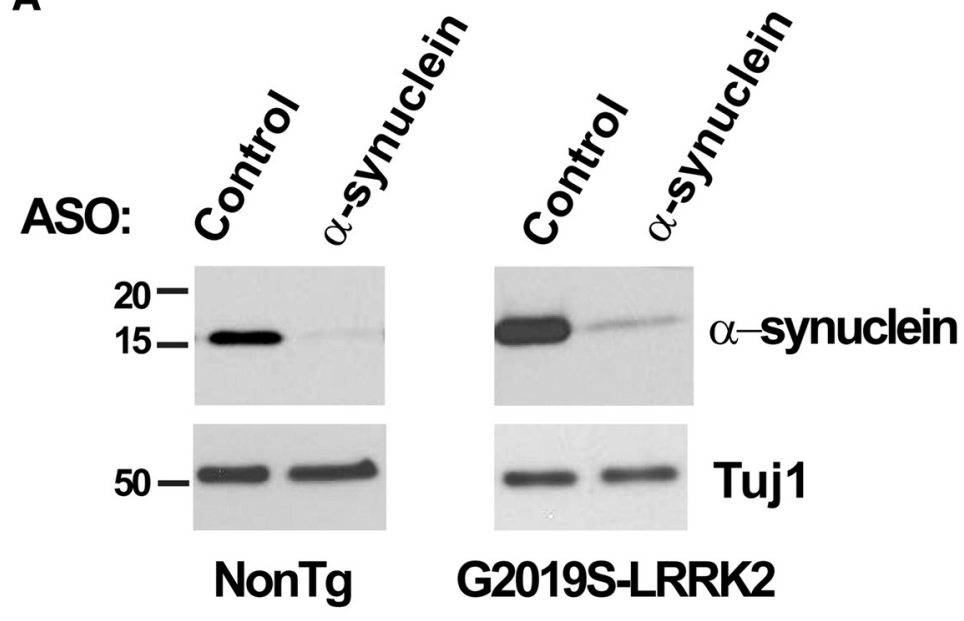

B
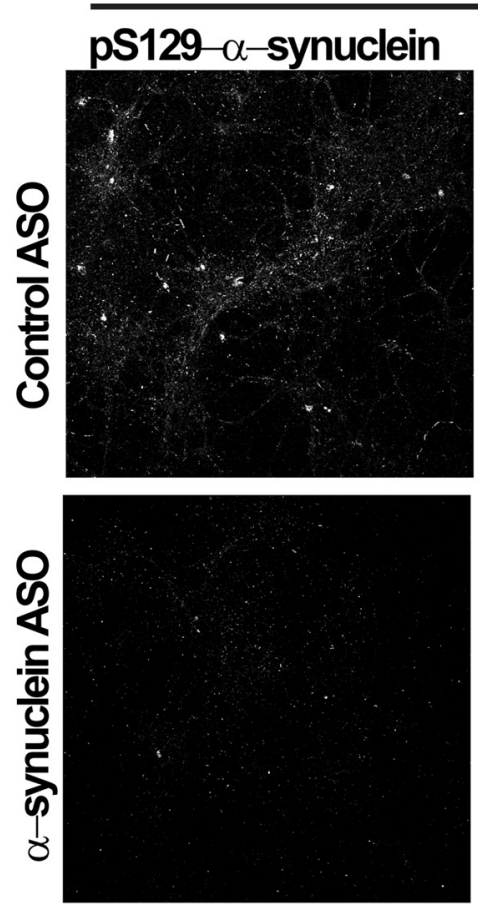

NonTg
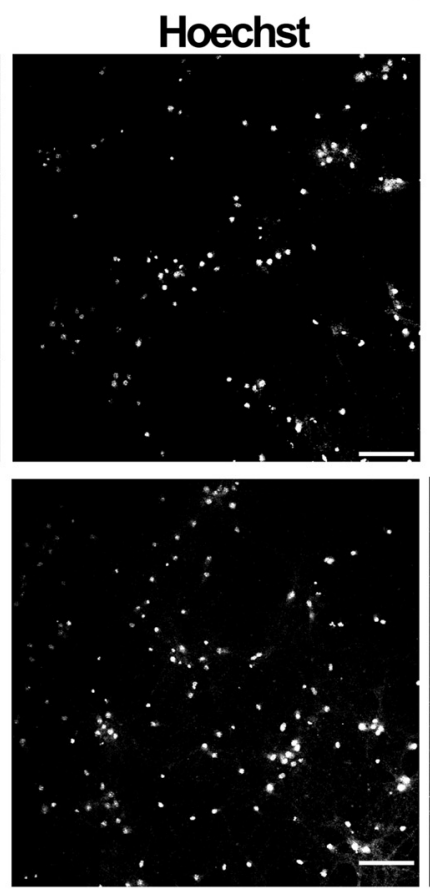

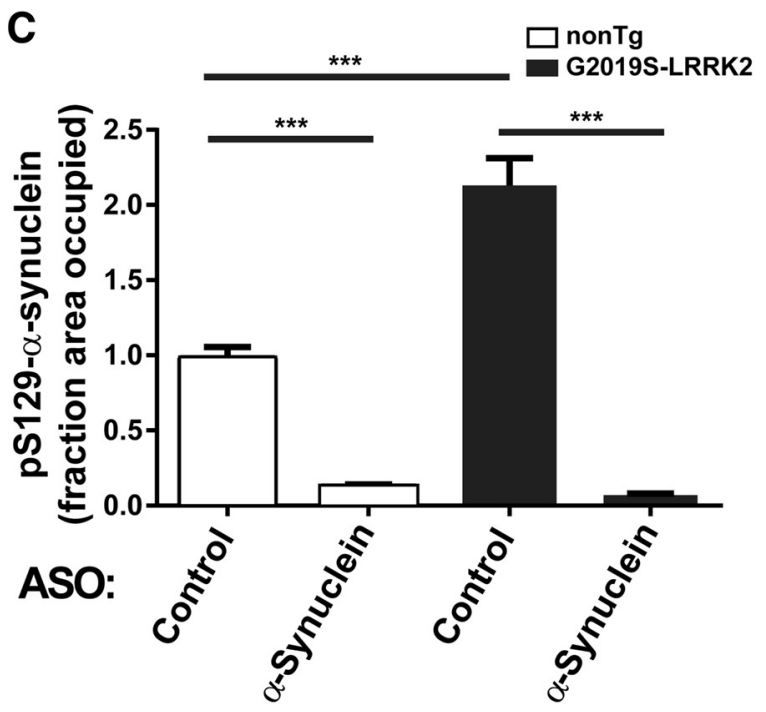

c
G2019S-LRRK2
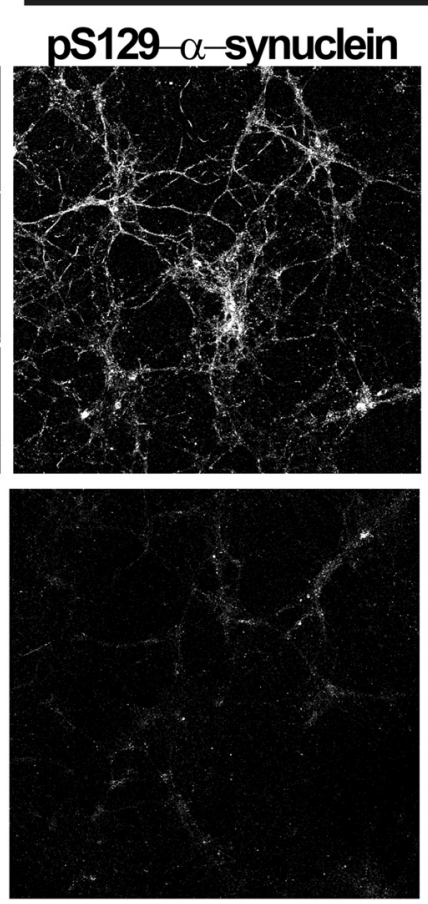
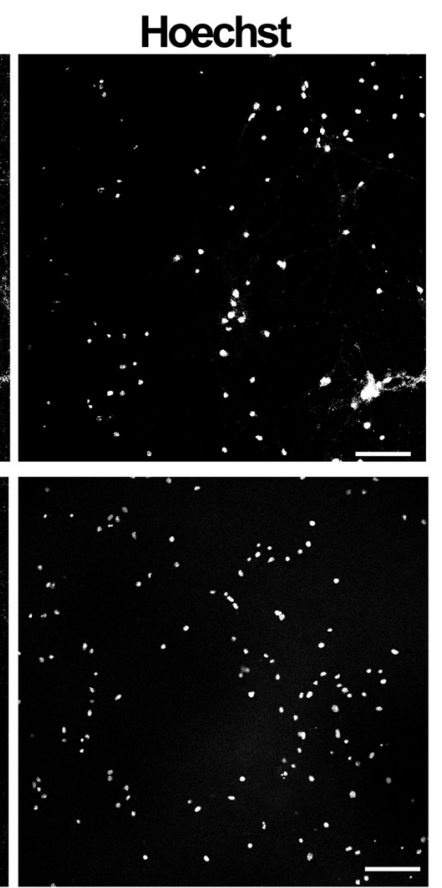

Figure 3. Reducing $\alpha$-synuclein levels inhibits formation of inclusions. A, Neurons from nonTg or G2019S-LRRK2-expressing mice were treated with $5 \mu \mathrm{m}$ control or $\alpha$-synuclein ASOs at DIV 7, lysates were collected $18 \mathrm{~d}$ later, and immunoblots were performed for total $\alpha$-synuclein or Tuj-1. Representative blots are shown. $\boldsymbol{B}$, Neurons from nonTg or G2019S-LRRK2-expressing mice were cotreated with $5 \mu \mathrm{m}$ control or $\alpha$-synuclein ASOs and $2.0 \mu \mathrm{g} / \mathrm{ml}$ fibrils. Neurons were fixed $18 \mathrm{~d}$ later, and immunofluorescence for pS129- $\alpha$-synuclein was performed to visualize inclusions. Representative confocal images are shown. Scale bars, $100 \mu \mathrm{m}$. C, Quantitation of pS129- $\alpha$-synuclein abundance in nonTg or G2019S-LRRK2-expressing primary neurons exposed to $2.0 \mu \mathrm{g} / \mathrm{ml}$ fibrils for $18 \mathrm{~d}$ with control or $\alpha$-synuclein ASOs. For each genotype, $N=20$ images from 2 independent experiments. ${ }^{* *} p<0.001$. Bar charts represent group mean. Error bars indicate SEM.

nonTg neurons (Fig. $2 B, C$ ). In contrast, neurons from WTLRRK2 mice had fewer inclusions relative to both nonTg and G2019S-LRRK2-expressing neurons. Confocal images show that in both nonTg, WT-LRRK2, and G2019S-LRRK2-expressing neurons, $\alpha$-synuclein inclusions colocalized with tau along axons (Fig. 2C). The somal inclusions in the G2019S-LRRK2 neurons were more abundant and the longer serpentine inclusions were more apparent compared with the smaller axonal pS129- $\alpha$ synuclein-positive puncta seen in the nonTg and WT-LRRK2expressing neurons (Fig. 2C).
Knockdown of endogenous $\alpha$-synuclein with ASOs

To determine the extent to which endogenous $\alpha$-synuclein levels contribute to the inclusion formation phenotype associated with G2019S-LRRK2 expression, antisense oligonucleotides were applied to neurons at DIV 7 , with or without $2 \mu \mathrm{g} / \mathrm{ml}$ of sonicated fibrils. Neurons were harvested for immunoblots or fixed for immunofluorescence 18 d later. $\alpha$-Synuclein ASOs substantially reduced levels of $\alpha$-synuclein in primary neurons from both nonTg and G2019S-LRRK2-expressing mice (Fig. 3A). Knockdown of $\alpha$-synuclein prevented formation of inclusions in the 
G2019S-LRRK2-expressing neurons (Fig. 3 B, C). Therefore, the increase in inclusion formation produced by G2019S-LRRK2 expression depends on levels of total $\alpha$-synuclein.

A proportion of $\alpha$-synuclein in G2019S-LRRK2-expressing neurons remains mobile in neurons with inclusions The susceptibility of $\alpha$-synuclein to form inclusions depends on a balance between $\alpha$-synuclein membrane association and cytosol localization (Burré et al., 2015). We hypothesized that expression of G2019S-LRRK2, associated with increased $\alpha$-synuclein levels (Fig. $1 B)$, may increase the mobile fraction of $\alpha$-synuclein. FRAP experiments characterize the membrane association of $\alpha$-synuclein in living neurons and show that disease-linked mutations in $\alpha$-synuclein reduce association with membranes and increase mobility (Fortin et al., 2005). FRAP experiments also preserve the membrane association of $\alpha$-synuclein in intact neurons, unlike biochemical experiments in which the neurons are lysed, causing $\alpha$-synuclein to dissociate from membranes. To perform these experiments, nonTg and G2019S-LRRK2-expressing neurons were transfected with $\alpha$-synuclein-GFP, which we and others have shown can be recruited into insoluble, phosphorylated inclusions after exogenous addition of fibrils (Volpicelli-Daley et al., 2014b; Osterberg et al., 2015). Sonicated fibrils were added at DIV 7 to the transfected neurons, and FRAP experiments were performed $18 \mathrm{~d}$ later (DIV 25). In control neurons at DIV 25 not exposed to fibrils, the percentage recovery of $\alpha$-synuclein-GFP was increased for G2019S-LRRK2-expressing neurons, with $\sim 30 \%$ recovery in nonTg neurons and 35\% for G2019SLRRK2-expressing neurons at $30 \mathrm{~s}$ after bleach (Fig. 4). Eighteen days after exposure to sonicated fibrils, fluorescence recovery was substantially reduced in nonTg neurons (5\% recovery) because $\alpha$-synuclein-GFP was sequestered into insoluble inclusions. However, in neurons expressing G2019S-LRRK2 that were exposed to sonicated fibrils, fluorescence recovery was only slightly impaired to $25 \%$ recovery. Although there were more pS129- $\alpha$-synuclein inclusions in neurons expressing G2019S-LRRK2 (Fig. 2), these neurons retained higher concentrations of mobile $\alpha$-synuclein-GFP compared with fibril-exposed nonTg neurons ( $5 \%$ for nonTg vs $25 \%$ for G2019S-LRRK2). Rates of recovery of fluorescence were estimated using the mixed effects linear models constructed with group and time effects and group $\times$ time interactions. Genotype groups, treatment groups (control vs fibril-treated), and the interaction between genotype and treatment was significant $(p<0.001)$. Thus, in neurons expressing G2019S-LRRK2, there is increased availability of mobile $\alpha$-synuclein that can be recruited into inclusions.

Inhibition of LRRK2 kinase activity rescues G2019S-LRRK2-mediated increases in $\alpha$-synuclein inclusions

To determine whether the increased inclusion formation in the G2019S-LRRK2 transgenic neurons depended on kinase activity, we used two structurally distinct LRRK2 kinase inhibitors. Both MLi-2 and PF-06447475 are potent and selective LRRK inhibitors; their chemical structures are shown in Figure 5A (Fell et al., 2015; Henderson et al., 2015). Neither inhibitor is known to inhibit an off-target enzyme (e.g., another kinase) with potency equal to LRRK2 or G2019SLRRK2. To compare these molecules directly, we found that both MLi-2 and PF-06447475 inhibited LRRK2 peptide phosphorylation with similar $\mathrm{IC}_{50}$ values of $1.1 \pm 0.2$ and $3.5 \pm 1.1$ nM, respectively (Fig. 5B), demonstrating exceptional potency for both molecules. A LRRK2 peptide phosphorylation assay in the presence of $1.1 \mathrm{nM}$ of MLi-2 or $3.5 \mathrm{nM}$ of PF-06447475 demonstrated that both inhibitors increased the $\mathrm{K}_{\mathrm{m}}$-ATP
A
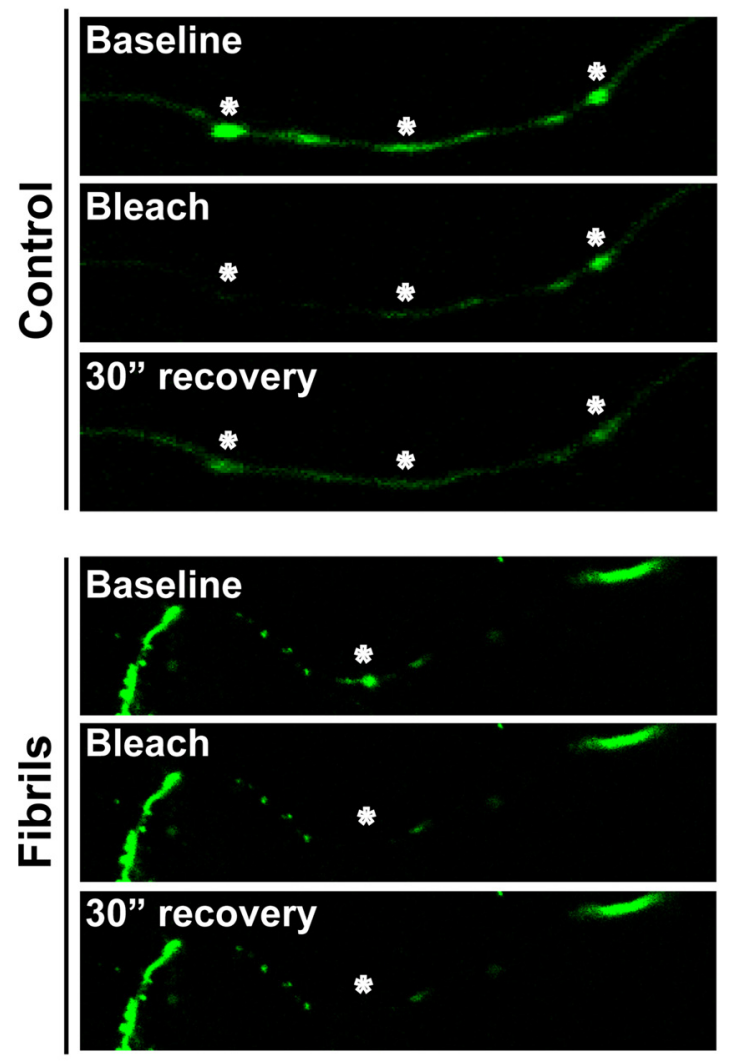

B $\quad \alpha$-Synuclein-GFP

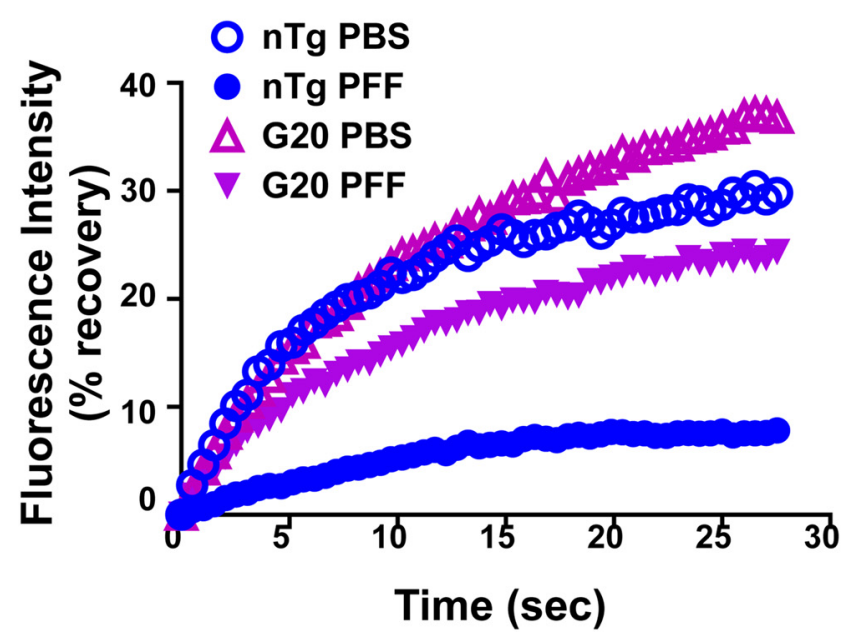

Figure 4. G2019S-LRRK2 expression increases $\alpha$-synuclein mobility after the formation of $\alpha$-synuclein inclusions. Primary hippocampal neurons were transfected on DIV 6 with $\alpha$-synuclein-GFP. The $2.0 \mu \mathrm{g} / \mathrm{ml}$ fibrils or were added, as indicated, on DIV 7, and FRAP experiments were performed $18 \mathrm{~d}$ later. $\boldsymbol{A}$, Representative images from FRAP experiments with primary neurons transfected with $\alpha$-synuclein-GFP. Fluorescence at baseline, immediately after the bleach, and $30 \mathrm{~s}$ after recovery are shown for control or fibril-treated neurons. In the neurons exposed to fibrils, only the smaller $\alpha$-synuclein-GFP puncta were bleached, and the longer serpentine inclusions were excluded. Asterisks indicate representative points where recordings were made. $\boldsymbol{B}$, Quantitation of fluorescence recovery measured every $0.27 \mathrm{~s}$. Fluorescence intensity is expressed as a percentage of the initial prebleach intensity. Individual values are reported as the group mean from an average of 30 individual $\alpha$-synuclein-GFP-positive puncta analyzed from three independent cultures. 
A

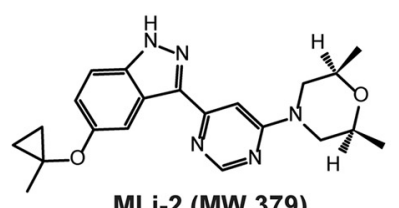

MLi-2 (MW 379)

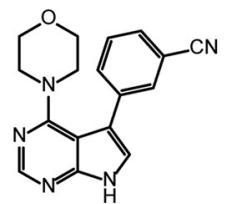

PF-475 (MW 305)
B

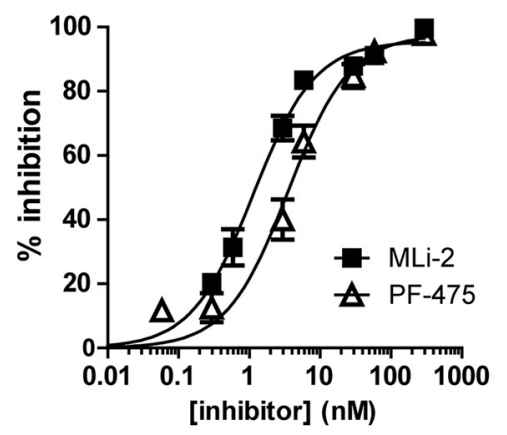

C

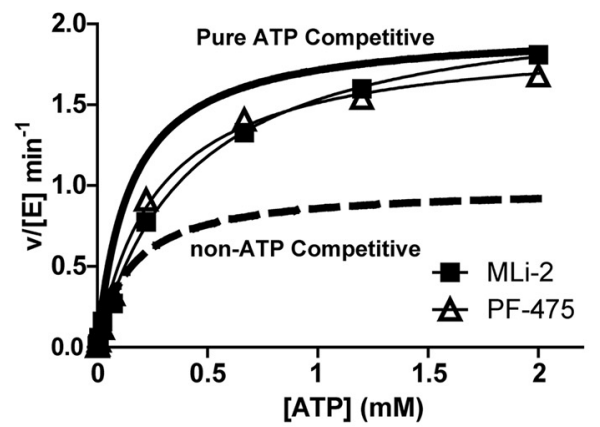

D

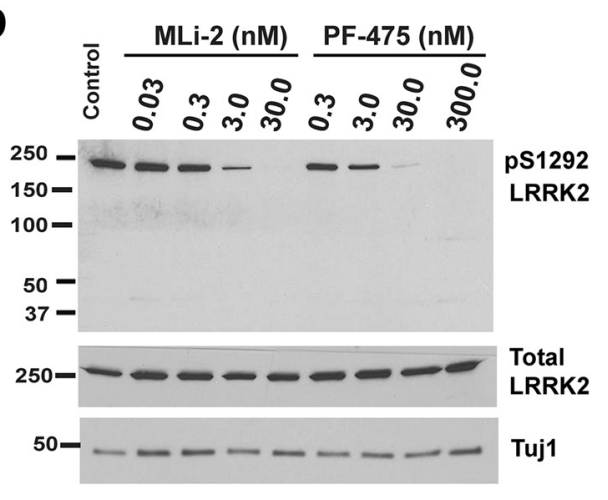

E

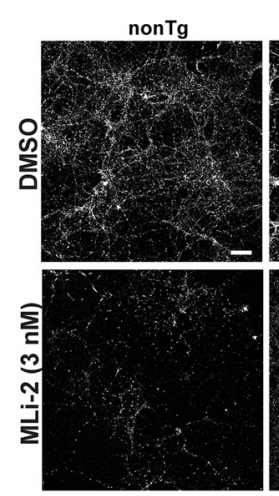

G2019S-LRRK2

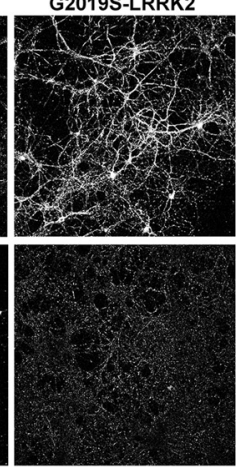

F 口nonTg $^{\text {nong }}$

F

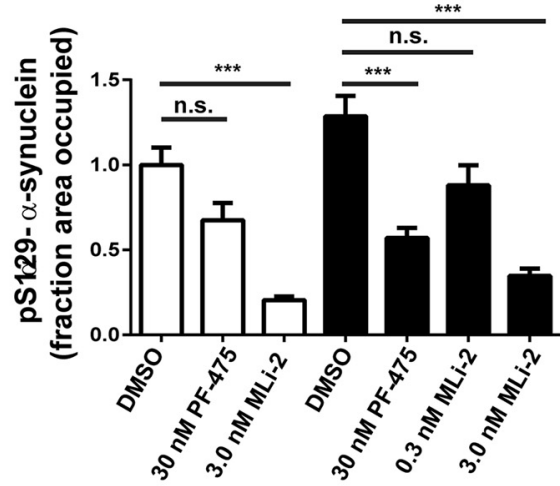

Figure 5. Inhibition of LRRK2 kinase activity reduces fibril-induced $\alpha$-synuclein inclusions in G2019S-LRRK2-expressing primary neurons. $A$, Structures of the LRRK2 kinase inhibitors, PF-06447475 (PF-475) and MLi-2. B, Recombinant GST-tagged human LRRK2 was incubated with LRRK2tide and [ $\gamma^{-}{ }^{32}$ P]ATP in buffer containing MLi-2 or PF-06447475 (0-1000 nM). MLi-2 and PF-06447475 inhibited LRRK2 peptide phosphorylation with an IC ${ }_{50}$ value of $1.1 \pm 0.2$ and $3.5 \pm 1.1 \mathrm{~nm}$, respectively. C, The $1.1 \mathrm{~nm}$ Mli2 or $3.5 \mathrm{~nm}$ PF-06447475 was incubated with recombinant LRRRK2 and peptide, with $0-2000 \mu \mathrm{m}\left[\gamma^{-}{ }^{32}\right.$ P]ATP. Both inhibitors increase LRRK2 $\mathrm{K}_{\mathrm{m}}$ ATP $(149.9 \pm 9.7,421.4 \pm 18.7$, and $272.3 \pm 14.3 \mu \mathrm{m}$ in presence of DMSO, MLi2, or PF-06447475, respectively) while leaving the $V_{\max }$ unchanged ( $1.97 \pm 0.03 \mathrm{~min}$ for all conditions). Curves represent the inhibitory profile of a theoretical purely competitive or non-ATP competitive inhibitor. D, Primary hippocampal neurons were treated with the indicated concentration of PF- $06447475, \mathrm{MLi}-2$, or DMSO control $\left(1.2 \times 10^{-4} \%\right.$ of media top DMSO concentration) for $18 \mathrm{~h}$ before the neurons were harvested into protein lysates. Immunoblots are shown for antibodies specific for pS1292-LRRK2, total LRRK2, and Tuj1 as a loading control. $\boldsymbol{E}$, Representative confocal images of primary neurons from nonTg or G2019S-LRRK2 BACs cotreated with $2.0 \mu \mathrm{g} / \mathrm{ml}$ fibrils, with or without $3.0 \mathrm{~nm}$ MLi-2 for $18 \mathrm{~d}$. Immunofluorescence using an antibody to pS129- $\alpha$-synuclein was performed to visualize inclusions. Scale bars, $100 \mu \mathrm{m}$. $\boldsymbol{F}$, Quantitation pS129- $\alpha$-synuclein abundance in nonTg or G2019SLRRK2-expressing primary neurons exposed to $2.0 \mu \mathrm{g} / \mathrm{ml}$ fibrils for $18 \mathrm{~d}$ in the absence or presence of indicated concentrations of PF- 06447475 or MLi-2. Ntg: DMSO, $N=70$ from 5

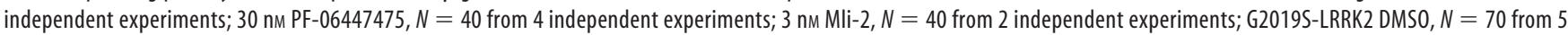
independent experiments; $30 \mathrm{~nm}$ PF- $06447475, N=40$ from 4 independent experiments; $3 \mathrm{~nm} \mathrm{MLi-2,N=} 40$ from 2 independent experiments; $0.3 \mathrm{~nm} M L \mathrm{~L}-2, N=40$ from 2 independent experiments. Bar charts represent group mean. Error bars indicate SEM. ${ }^{* *} p<0.001$.

$(149.9 \pm 9.7,421.4 \pm 18.7$, and $272.3 \pm 14.3 \mu \mathrm{M}$ in the presence of DMSO, MLi-2, or PF-06447475, respectively) while leaving the $V_{\max }$ unchanged $(1.97 \pm 0.03 \mathrm{~min})$, suggesting a near-perfect ATP-competitive inhibitory profile that is comparable between the two molecules (Fig. 5C). These results show that MLi-2 and PF-06447475 inhibit LRRK2 in a similar, ATP-competitive manner and with similar potencies and have nanomolar inhibition profiles at physiological ATP concentrations.

To empirically determine the concentration of inhibitor that could block LRRK2 kinase activity in primary neurons, we treated neurons using concentrations of PF-06447475 ranging from 0.3 to $300 \mathrm{nM}$, and MLi-2 ranging from 0.03 to $30 \mathrm{~nm}$. Immunoblots of the authentic LRRK2 autophosphorylation site pS1292-LRRK2 were used to empirically assess LRRK2 inhibition (Sheng et al., 2012) (Fig. 5D). Both PF-06447475 and MLi-2 potently reduced levels of pS1292-LRRK2 compared with vehicle (DMSO)-treated neurons. Immunoblots of total LRRK2 demonstrated that neither PF-06447475 nor MLi-2, even at the highest concentrations tested and for $18 \mathrm{~d}$ incubation in neuronal media, reduced total LRRK2 levels (Fig. 5D).
To analyze the effects of PF-06447475 and MLi-2 on pS129$\alpha$-synuclein inclusions, neurons were cotreated with either PF06447475 or MLi- 2 and $2 \mu \mathrm{g} / \mathrm{ml}$ of sonicated fibrils, and neurons were processed for analysis $18 \mathrm{~d}$ later. Treatment with $30 \mathrm{nM}$ PF-06447475 substantially reduced the abundance of inclusions in neurons expressing G2019S-LRRK2 by 55\% (Fig. $5 F$ ). Treatment with $3.0 \mathrm{nM}$ of $\mathrm{MLi}-2$ reduced the abundance of inclusions in both nonTg and G2019S-LRRK2-expressing neurons by 75\%$80 \%$. These data demonstrate that reduction of LRRK2 kinase activity inhibits inclusion formation and rescues the phenotype associated with G2019S-LRRK2 expression.

Enhanced inclusions in TH-positive neurons in the SNpc of G2019S-LRRK2-expressing rats

Previously, we found that G2019S-LRRK2 BAC rats express high levels of mutant LRRK2 in dopaminergic SNpc cells, whereas littermate nonTg rats express very low or no LRRK2 in the SNpc (West et al., 2014). Fibrils directly injected into the rat brain show robust inclusions in SNpc neurons after as little as $30 \mathrm{~d}$ (Paumier et al., 2015). To determine whether G2019S-LRRK2 expression in rats could directly enhance inclusion formation in dopaminergic 

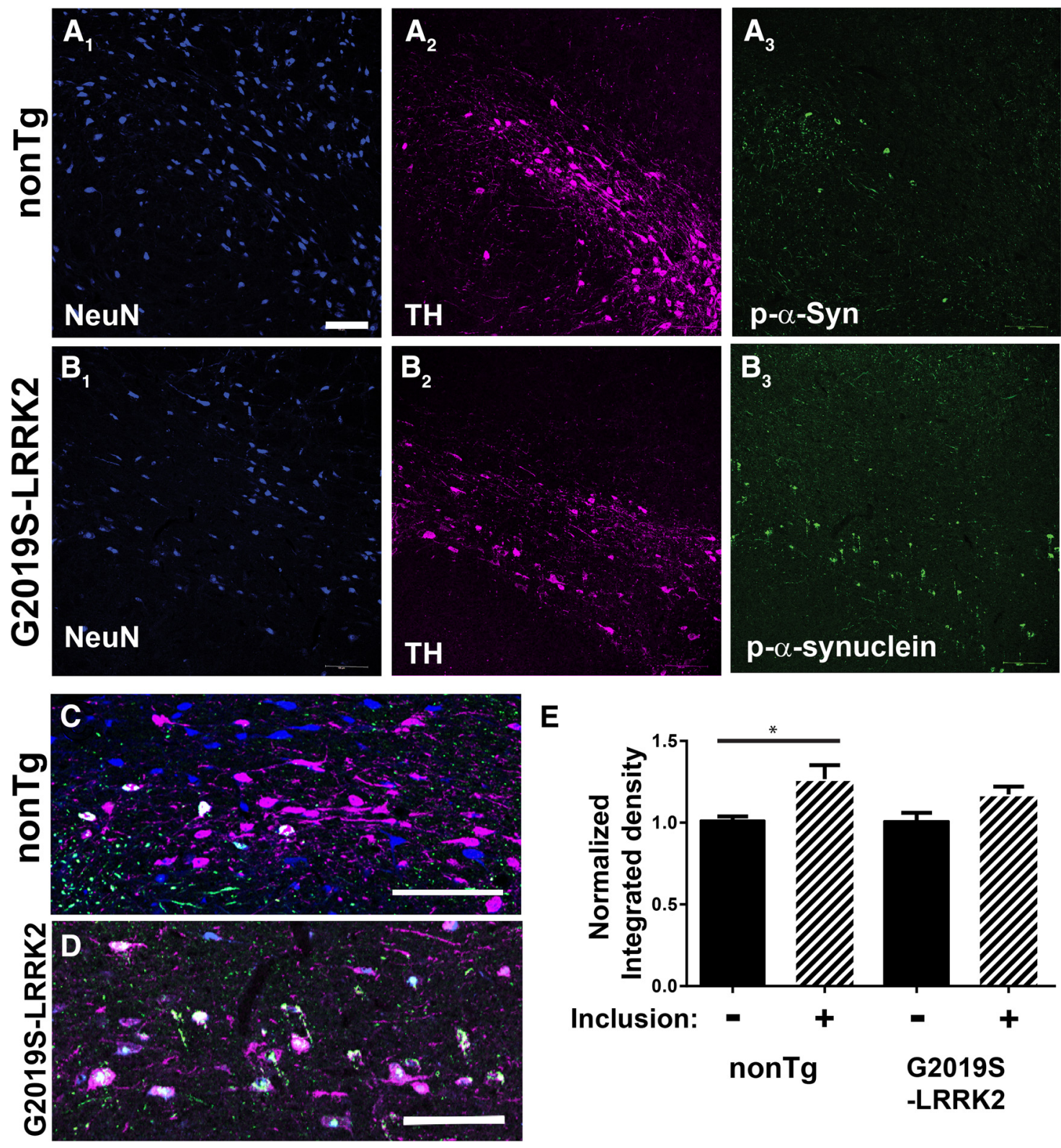

E

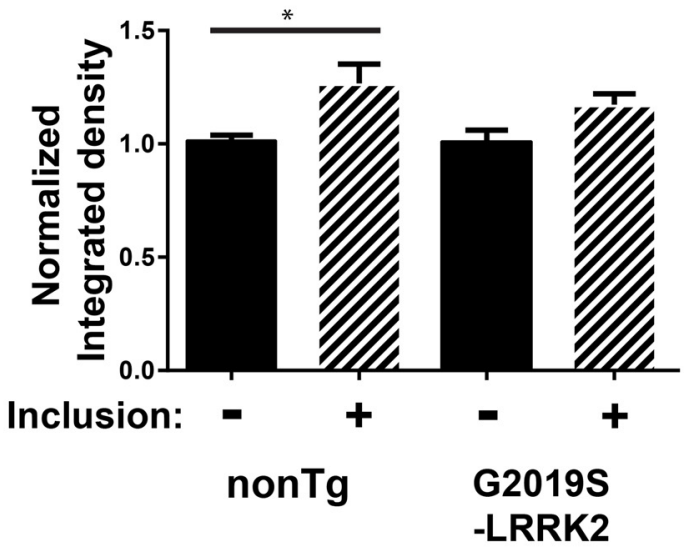

Figure 6. pS129- $\alpha$-synuclein inclusions in the SNpc localize to TH neurons. The $20 \mu \mathrm{g}$ of fibrils was injected into the SNpc in 10- to 12-week old nonTg $(A, C)$ or littermate G2019S-LRRK2 BAC rats $(\boldsymbol{B}, \boldsymbol{D})$. Rats were killed 4 weeks after injection, and confocal analysis was performed in the SNpc to image neuronal nuclei (NeuN, blue), TH in SNpc dopaminergic neurons (TH, magenta), and pS129- $\alpha$-synuclein inclusions (green). pS129- $\alpha$-synuclein inclusions localized to TH-positive neurons. $\boldsymbol{E}$, Confocal images of TH immunofluorescence were captured, and the normalized integrated density was measured for neurons with and without inclusions in both nonTg and G2019S-LRRK2-expressing rats. $N=100$ TH-positive neurons analyzed per group (50 with inclusions), from $N=3$ nonTg and $N=3$ G2019S-BAC rats. ${ }^{*} p<0.05$ (independent $t$ test). Error bars indicate SEM. Scale bars, $100 \mu \mathrm{m}$.

neurons, we injected fibrils into the right $\mathrm{SNpc}$, and equivalent concentrations of $\alpha$-synuclein monomer control into the left SNpc, of G2019S-LRRK2 BAC transgenic rats and littermate nonTg controls. After 1 month, the same time course used for the primary neuronal experiments, rats were perfused and immunofluorescence for pS129- $\alpha$-synuclein was performed. To examine the subcellular distribution of $\alpha$-synuclein inclusions within the $\mathrm{SNpc}$, we first performed triple labeling immunofluorescence for $\mathrm{TH}$ to identify SNpc dopamine neurons, and NeuN to label all neuronal nuclei. These results demonstrated that all of the pS129- $\alpha$ synuclein inclusions localized to dopaminergic neurons, in both G2019S-LRRK2 BAC and nonTg controls (Fig. 6). To determine whether inclusion formation affected expression of TH as previously shown (Paumier et al., 2015), we quantified fluorescent levels of TH in $\mathrm{SNpc}$ neurons with and without inclusions in both nonTg and
G2019S-LRRK2-expressing rats. Levels of TH were not reduced, but slightly higher, in inclusion-bearing neurons in both nonTg and G2019S-LRRK2-expressing rats (Fig. 6E).

Although the G2019S-LRRK2 BAC rat does not show dopaminergic neurodegeneration or changes in TH expression in the striatum due to the transgene expression (Daher et al., 2015), we next sought to determine whether the fibril or monomer injection caused a loss of neurons in either G2019S-LRRK2 or nonTg rats that might confound our analysis 1 month after injection. We performed unbiased stereology of TH-positive neurons in the SNpc and found a normal cell count in both nonTg and G2019SLRRK2-expressing rats. TH expression in the dorsal striatum was also unchanged (Fig. 7C,D).

To determine whether the abundance of inclusions was higher in SNpc neurons in G2019S-LRRK2 rats, we counted the number of 
A
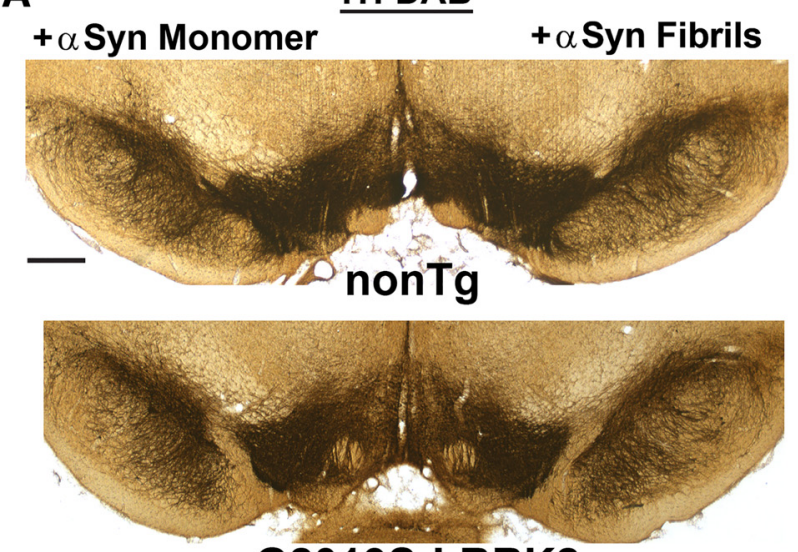

C

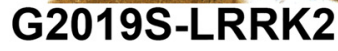

B
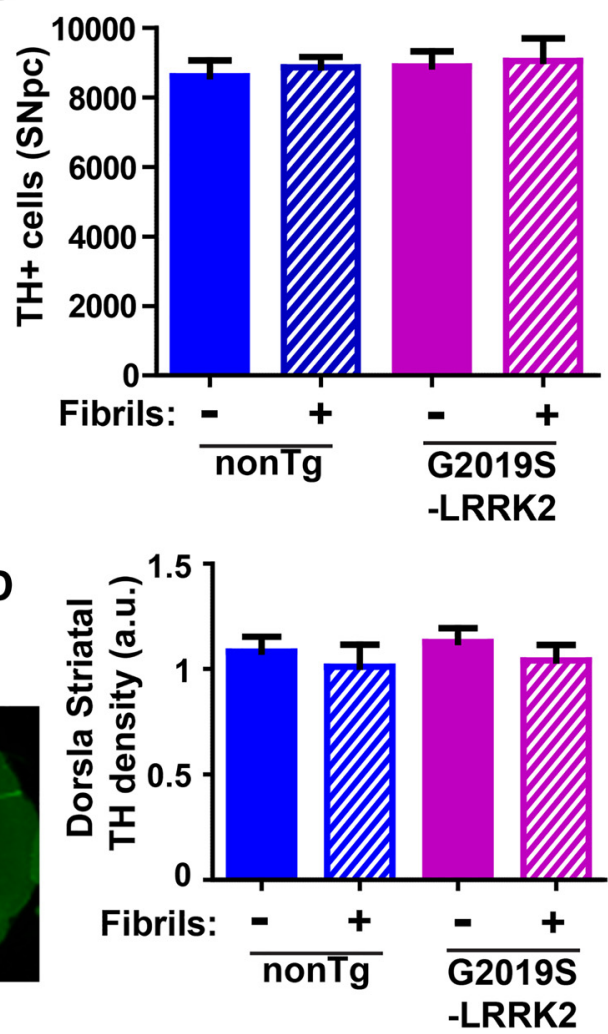

Figure 7. Lack of neurodegeneration in G2019S-LRRK2 BAC rats 1 month after fibrils. $A$, Representative immunohistochemistry for TH in SNpc sections from nonTg and G2019S-LRRK2 BAC transgenic rats. $\boldsymbol{B}$, Unbiased stereological counts of TH-positive neurons in the fibril-injected and contralateral monomer-injected SNpc. nonTg: $N=8$ rats; $G 2019 S$-LRRK2: $N=4$ rats. Error bars indicate SEM. C, Representative images showing TH fiber density in the striatum. $D$, Quantification of dorsal striatum TH fiber density using LiCOR analysis. SNpc nonTg: $N=8$ rats; $G 2019 S-L R R K 2$ : $N=4$ rats. Error bars indicate SEM.

cell bodies harboring pS129- $\alpha$-synuclein inclusions through the SNpc using unbiased stereology (Fig. 8). pS129- $\alpha$-synucleinpositive inclusions were never found in the contralateral monomerinjected side (Fig. 8A,B). Higher-magnification images revealed abundant neurite pS129- $\alpha$-synuclein reactivity (Fig. $8 C$, arrows), spherical pS129- $\alpha$-synuclein-positive inclusions (Fig. $8 C, D$, asterisk tag), and neurons with diffuse pS129- $\alpha$-synuclein staining (Fig. $8 C$, + tag). Stereological counts through the entire SNpc demonstrated that G2019S-LRRK2 BAC rats had double the number of neurons with spherical pS129- $\alpha$-synuclein inclusions compared with littermate controls (Fig. $8 E$ ).

\section{Discussion}

In this study, we have made several novel observations. First, using a robust model of $\alpha$-synuclein pathology, G2019S-LRRK2 enhanced $\alpha$-synuclein inclusions in primary hippocampal neurons compared with neurons overexpressing WT-LRRK2. This effect was apparent at $18 \mathrm{~d}$ after $\alpha$-synuclein fibril exposure, but a difference could not be detected earlier at $7 \mathrm{~d}$ after $\alpha$-synuclein fibril exposure when inclusions were more minimal. The effects of G2019S-LRRK2 expression could be mitigated with nanomolar concentrations of potent and selective LRRK2 kinase inhibitors, suggesting that G2019S-LRRK2 kinase activity underlies the acceleration of $\alpha$-synuclein into pathologic inclusions. This study demonstrates that a kinase inhibitor can impair pS129- $\alpha$ synuclein-positive inclusion pathology in primary neurons. We demonstrated that G2019S-LRRK2 expression in vivo also enhanced $\alpha$-synuclein inclusions in dopamine neurons of the SNpc, which further supports a link between the G2019S LRRK2 muta- tion and PD pathogenesis. Overall, our findings provide specific evidence for a pathological interaction between G2019S-LRRK2 expression and $\alpha$-synuclein.

We first explored the effects of G2019S-LRRK2 by using primary neuron cultures and found that G2019S-LRRK2 expression increased $\alpha$-synuclein inclusions, but only after extended time points. These results imply that G2019S-LRRK2 expression may not affect internalization of fibrils or the initial seeding reaction, as these effects would be expected to be observed at the initial time points when robust pS129- $\alpha$-synuclein staining could be measured. However, G2019S-LRRK2 did impact the accumulation of $\alpha$-synuclein into abnormal inclusions over time, with a consistent increase in pS129- $\alpha$-synuclein reactivity. This effect resulted from expression of the G2019S-LRRK2 mutation and not from overexpressing LRRK2 because similar levels of WTLRRK2 driven from the same BAC construct, but without the G2019S mutation, did not drive increased pS129- $\alpha$-synucleinpositive inclusion formation.

Based on these observations, we speculate that G2019SLRRK2 may augment the process of $\alpha$-synuclein inclusion formation once the process is initiated. In potential support of our observations, it has been reported that G2019S-LRRK2 expression enhances $\alpha$-synuclein aggregation in mice that also conditionally overexpress human A53T- $\alpha$-synuclein (Lin et al., 2009; Daher et al., 2012), although an important difference is that, in the current study, G2019S-LRRK2 enhanced $\alpha$-synuclein inclusions in the context of endogenous wild-type $\alpha$-synuclein expression. Another study demonstrated that increased levels of LRRK2 


\section{NonTg}
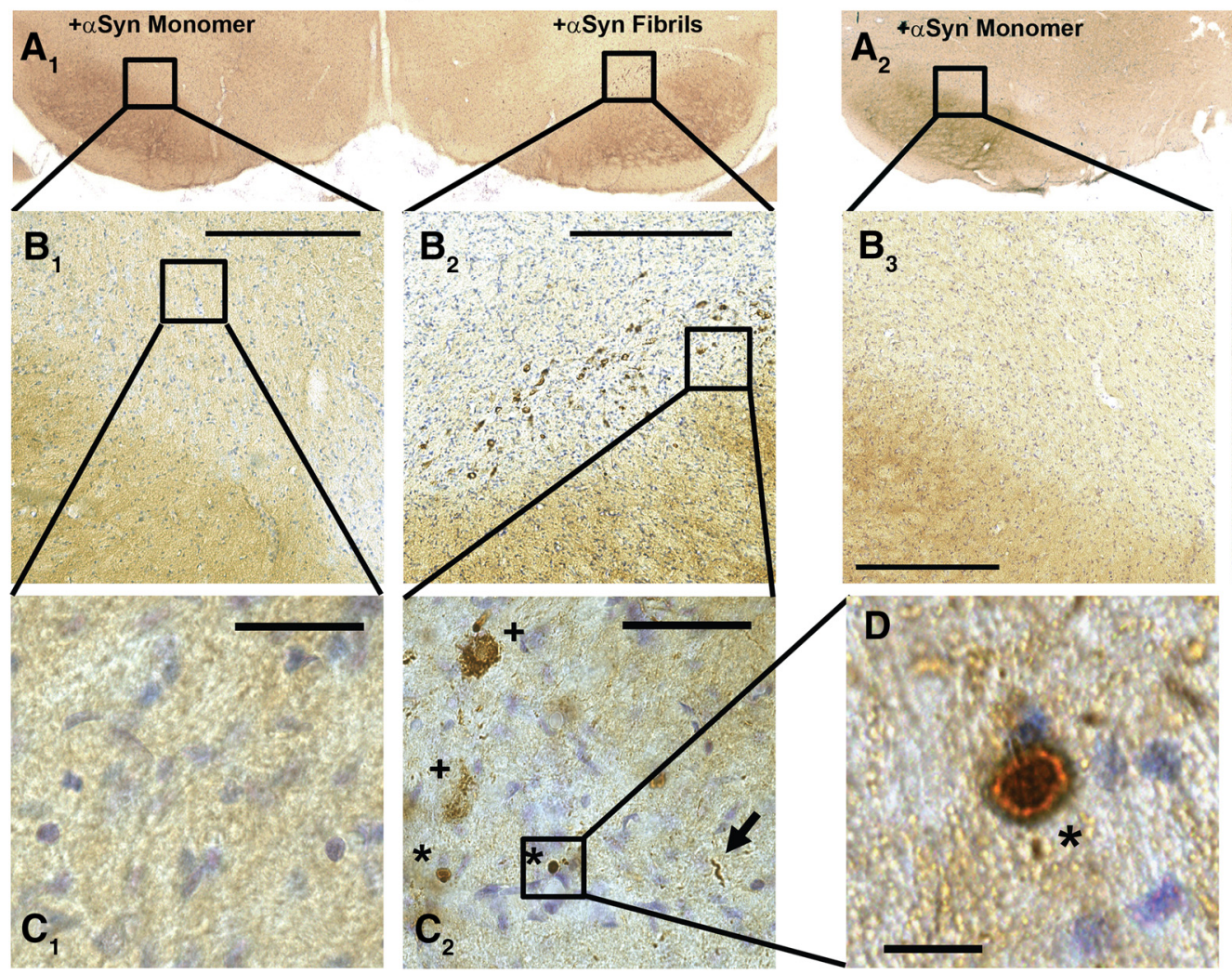

G2019S-LRRK2
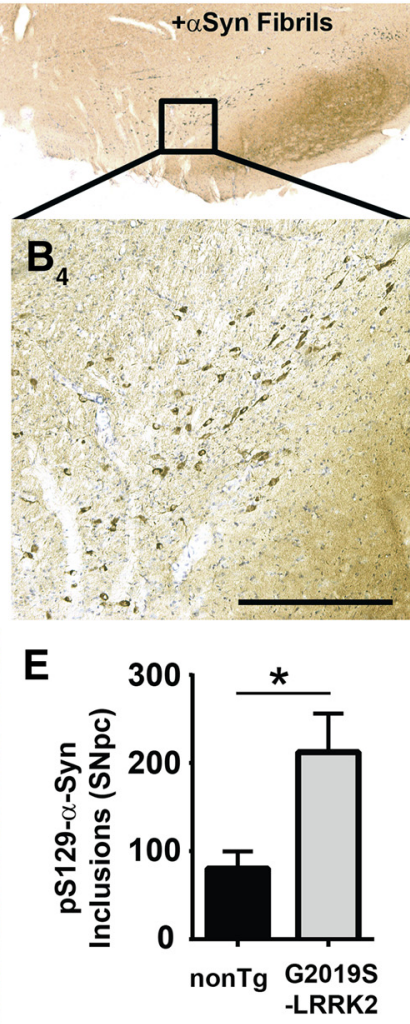

Figure 8. G2019S-LRRK2 expression increases the number of pS129- $\alpha$-synuclein inclusions in the SNpc after fibril exposure. The $20 \mu \mathrm{g}$ of fibrils (right side) or monomeric $\alpha$-synuclein (left side) was injected into the SNpc in 10- to 12-week-old male G2019S-LRRK2 BAC or littermate control nonTg rats. At 4 weeks later, animals were perfused and immunohistochemistry was performed for pS129- $\alpha$-synuclein by DAB staining with Nissl counterstain. $A, B$, Representative coronal sections of the midbrain from nonTg and G2019S-LRRK2 BAC rats showing inclusion distribution through the SNpc. Scale bars, $250 \mu \mathrm{m} . \boldsymbol{B}_{\boldsymbol{1}}, \boldsymbol{B}_{\mathbf{3}}, \boldsymbol{C}_{\boldsymbol{1}}$, A lack of staining in the contralateral alpha-synuclein-monomer-injected side. $\boldsymbol{B}_{\mathbf{2}}, \boldsymbol{B}_{\mathbf{4}}$, Neuronal soma with p-S129-alpha-synuclein positive staining ipsilateral to the injection. $\boldsymbol{C}_{2}$, A variety of pS129-alpha-synuclein positive structures that include dense circular Lewy-body like inclusions highlighted with an asterisk. $\boldsymbol{C}_{1}$, A lack of staining in the contralateral $\alpha$-synuclein-monomer-injected side. $\boldsymbol{C}_{2}$, A variety of pS129- $\alpha$-synuclein-positive structures that include dense circular Lewy-body like inclusions highlighted with an asterisk. ${ }^{+}$Neurons that show diffuse staining and much smaller inclusions. Arrow indicates serpentine neurite structures. Scale bars, $50 \mu \mathrm{m}$. $\boldsymbol{D}$, High-magnification image of a circular inclusion with a dense core of pS129- $\alpha$-synuclein surrounded by a halo. Scale bar, $5 \mu \mathrm{m}$. $\boldsymbol{E}$, Unbiased stereological counts of pS129- $\alpha$-synuclein inclusions ( ${ }^{*}$ structures) in the SNpc from five G2019S-LRRK2 BAC rats and five nonTg littermate controls. ${ }^{*} p<0.01$ (independent $t$ test). Error bars indicate SEM. There were no instances of $\mathrm{p} S 129$ - $\alpha$-synuclein inclusions in the contralateral side of any animal.

were found in brain areas from postmortem PD tissue that had abundant Lewy bodies, but not in brain regions without pathology, and LRRK2 and $\alpha$-synuclein could be coimmunoprecipitated from these human brain lysates (Guerreiro et al., 2013).

Recent studies suggest that the reduced association of $\alpha$-synuclein with membranes may be a critical step in $\alpha$-synuclein-linked pathogenesis that promotes inclusion formation (Burré et al., 2015). Because $\alpha$-synuclein and LRRK2 can localize to similar membrane compartments, such as synapse vesicles and endosomes (Clayton and George, 1999; Biskup et al., 2006; Lee et al., 2010; Boassa et al., 2013; Schreij et al., 2015), we hypothesized that G2019S-LRRK2 may affect the membrane association of $\alpha$-synuclein to promote recruitment into inclusions. We chose FRAP experiments to measure this process in intact neurons because $\alpha$-synuclein readily dissociates from membranes after the lysis of cells or homogenization of brain tissue. FRAP imaging of intact neurons can detect transient membrane association of $\alpha$-synuclein at the presynaptic terminal (Fortin et al., 2005). FRAP experiments previously demonstrated that the disease-associated A30P mutation in $\alpha$-synuclein enhances mobility at the presynaptic terminal, likely because of a reduced association with membranes (Fortin et al., 2005). Here, we found that the pool of mobile cytoplasmic $\alpha$-sy- nuclein was higher in G2019S-LRRK2 compared with control neurons. After fibril exposure, $\alpha$-synuclein mobility was largely immobilized in nonTg neurons after inclusion formation, similar to previous reports (Osterberg et al., 2015). However, in G2019S-LRRK2 neurons, $\alpha$-synuclein mobility was only reduced. Thus, a substantial pool of mobile $\alpha$-synuclein persisted in neurons expressing G2019S-LRRK2, and this is the pool that is known to contribute directly to the development of $\alpha$-synuclein inclusions.

As we observed increased levels of mobile $\alpha$-synuclein in G2019S-LRRK2 neurons in primary culture, one possibility is that the enhanced mobility results from increased levels of $\alpha$-synuclein in the cytosolic pool that do not form $\alpha$-helical conformations (Dettmer et al., 2015b). Because neurons expressing WT-LRRK2 show significantly reduced levels of $\alpha$-synuclein, we do not predict these neurons to have enhanced mobility of $\alpha$-synuclein, although future experiments are required to assess this prediction. Increased levels of cytosolic $\alpha$-synuclein may be more susceptible to forming pS129- $\alpha$-synuclein $\beta$-sheet structures. The mass-action hypothesis for neurodegenerative disease supposes that modest upregulations in the expression of normal protein sequences over time can lead to protein aggregation and disease (Singleton et al., 2004). The discovery that multiplications 
of the SNCA gene drive aggressive PD phenotypes and pathologies demonstrate increased $\alpha$-synuclein expression can drive PD susceptibility (Singleton et al., 2003). Here, we hypothesize that the G2019S-LRRK2 mutation may contribute to PD susceptibility through enhancing mobile pools of $\alpha$-synuclein in neurons.

We were able to rescue the phenotypes associated with G2019S-LRRK2 expression in two ways. First, antisense oligonucleotides that lowered levels of $\alpha$-synuclein substantially reduced fibril-induced inclusion formation, in both G2019S-LRRK2expressing neurons and nonTg control neurons. Second, we were able to use two structurally distinct but near-equally potent LRRK2 small-molecule inhibitors to block the enhanced inclusion formation associated with G2019S-LRRK2 expression. Both approaches have potential clinical application for novel neuroprotection strategies in LRRK2-linked PD, and it will be important to fully explore these opportunities in vivo and in other preclinical models of PD and other neurodegenerative diseases.

Although we have not resolved why G2019S-LRRK2 neurons have increased $\alpha$-synuclein mobility and expression, one potential explanation may be related to G2019S-LRRK2-impaired autophagy, specifically chaperone-mediated autophagy, and lysosomal clearance of mobile $\alpha$-synuclein (Friedman et al., 2012; Orenstein et al., 2013; Henry et al., 2015). LRRK2 may also directly affect $\alpha$-synuclein synthesis rates (Martin et al., 2014). Recently discovered Rab LRRK2 substrates, such as Rab10a that G2019S-LRRK2, can phosphorylate and inactivate are attractive candidates that may affect $\alpha$-synuclein clearance mechanisms (Steger et al., 2016). Alternatively or potentially in complement to degradative mechanisms, G2019S-LRRK2 expression in neurons may upregulate synaptic activity (Beccano-Kelly et al., $2015)$, thereby upregulating $\alpha$-synuclein and the potential for $\alpha$-synuclein in the mobile pool (Fortin et al., 2005). Future studies will be required to explore these possibilities and help shed light on pathogenic mechanisms important for $\alpha$-synucleinlinked diseases and targets for intervention and neuroprotection.

\section{References}

Beccano-Kelly DA, Volta M, Munsie LN, Paschall SA, Tatarnikov I, Co K, Chou P, Cao LP, Bergeron S, Mitchell E, Han H, Melrose HL, Tapia L, Raymond LA, Farrer MJ, Milnerwood AJ (2015) LRRK2 overexpression alters glutamatergic presynaptic plasticity, striatal dopamine tone, postsynaptic signal transduction, motor activity and memory. Hum Mol Genet 24:1336-1349. CrossRef Medline

Bennett CF, Swayze EE (2010) RNA targeting therapeutics: molecular mechanisms of antisense oligonucleotides as a therapeutic platform. Annu Rev Pharmacol Toxicol 50:259-293. CrossRef Medline

Biskup S, Moore DJ, Celsi F, Higashi S, West AB, Andrabi SA, Kurkinen K, Yu SW, Savitt JM, Waldvogel HJ, Faull RL, Emson PC, Torp R, Ottersen OP, Dawson TM, Dawson VL (2006) Localization of LRRK2 to membranous and vesicular structures in mammalian brain. Ann Neurol 60: 557-569. CrossRef Medline

Boassa D, Berlanga ML, Yang MA, Terada M, Hu J, Bushong EA, Hwang M, Masliah E, George JM, Ellisman MH (2013) Mapping the subcellular distribution of alpha-synuclein in neurons using genetically encoded probes for correlated light and electron microscopy: implications for Parkinson's disease pathogenesis. J Neurosci 33:2605-2615. CrossRef Medline

Bousset L, Pieri L, Ruiz-Arlandis G, Gath J, Jensen PH, Habenstein B, Madiona K, Olieric V, Böckmann A, Meier BH, Melki R (2013) Structural and functional characterization of two alpha-synuclein strains. Nat Commun 4:2575. CrossRef Medline

Burré J, Sharma M, Südhof TC (2015) Definition of a molecular pathway mediating alpha-synuclein neurotoxicity. J Neurosci 35:5221-5232. CrossRef Medline

Chartier-Harlin MC, Kachergus J, Roumier C, Mouroux V, Douay X, Lincoln S, Levecque C, Larvor L, Andrieux J, Hulihan M, Waucquier N, Defebvre L, Amouyel P, Farrer M, Destée A (2004) Alpha-synuclein locus dupli- cation as a cause of familial Parkinson's disease. Lancet 364:1167-1169. CrossRef Medline

Clayton DF, George JM (1999) Synucleins in synaptic plasticity and neurodegenerative disorders. J Neurosci Res 58:120-129. CrossRef Medline

Dächsel JC, Behrouz B, Yue M, Beevers JE, Melrose HL, Farrer MJ (2010) A comparative study of Lrrk2 function in primary neuronal cultures. Parkinsonism Relat Disord 16:650-655. CrossRef Medline

Daher JP, Pletnikova O, Biskup S, Musso A, Gellhaar S, Galter D, Troncoso JC, Lee MK, Dawson TM, Dawson VL, Moore DJ (2012) Neurodegenerative phenotypes in an A53T alpha-synuclein transgenic mouse model are independent of LRRK2. Hum Mol Genet 21:2420-2431. CrossRef Medline

Daher JP, Volpicelli-Daley LA, Blackburn JP, Moehle MS, West AB (2014) Abrogation of alpha-synuclein-mediated dopaminergic neurodegeneration in LRRK2-deficient rats. Proc Natl Acad Sci U S A 111:9289-9294. CrossRef Medline

Daher JP, Abdelmotilib HA, Hu X, Volpicelli-Daley LA, Moehle MS, Fraser KB, Needle E, Chen Y, Steyn SJ, Galatsis P, Hirst WD, West AB (2015) Leucine-rich repeat kinase 2 (LRRK2) pharmacological inhibition abates alpha-synuclein gene-induced neurodegeneration. J Biol Chem 290: 19433-19444. CrossRef Medline

Dettmer U, Selkoe D, Bartels T (2015a) New insights into cellular alphasynuclein homeostasis in health and disease. Curr Opin Neurobiol 36: 15-22. CrossRef Medline

Dettmer U, Newman AJ, Soldner F, Luth ES, Kim NC, von Saucken VE, Sanderson JB, Jaenisch R, Bartels T, Selkoe D (2015b) Parkinsoncausing alpha-synuclein missense mutations shift native tetramers to monomers as a mechanism for disease initiation. Nat Commun 6:7314. CrossRef Medline

Dettmer U, Newman AJ, Soldner F, Luth ES, Kim NC, von Saucken VE, Sanderson JB, Jaenisch R, Bartels T, Selkoe D (2015c) Corrigendum: Parkinson-causing alpha-synuclein missense mutations shift native tetramers to monomers as a mechanism for disease initiation. Nat Commun 6:8008. CrossRef Medline

Duda JE, Lee VM, Trojanowski JQ (2000) Neuropathology of synuclein aggregates. J Neurosci Res 61:121-127. CrossRef Medline

Fell MJ, Mirescu C, Basu K, Cheewatrakoolpong B, DeMong DE, Ellis JM, Hyde LA, Lin Y, Markgraf CG, Mei H, Miller M, Poulet FM, Scott JD, Smith MD, Yin Z, Zhou X, Parker EM, Kennedy ME, Morrow JA (2015) MLi-2, a potent, selective, and centrally active compound for exploring the therapeutic potential and safety of LRRK2 kinase inhibition. J Pharmacol Exp Ther 355:397-409. CrossRef Medline

Fletcher TL, De Camilli P, Banker G (1994) Synaptogenesis in hippocampal cultures: evidence indicating that axons and dendrites become competent to form synapses at different stages of neuronal development. J Neurosci 14:6695-6706. Medline

Fortin DL, Nemani VM, Voglmaier SM, Anthony MD, Ryan TA, Edwards RH (2005) Neural activity controls the synaptic accumulation of alphasynuclein. J Neurosci 25:10913-10921. CrossRef Medline

Friedman LG, Lachenmayer ML, Wang J, He L, Poulose SM, Komatsu M, Holstein GR, Yue Z (2012) Disrupted autophagy leads to dopaminergic axon and dendrite degeneration and promotes presynaptic accumulation of alpha-synuclein and LRRK2 in the brain. J Neurosci 32:7585-7593. CrossRef Medline

Giasson BI, Duda JE, Quinn SM, Zhang B, Trojanowski JQ, Lee VM (2002) Neuronal alpha-synucleinopathy with severe movement disorder in mice expressing A53T human alpha-synuclein. Neuron 34:521-533. CrossRef Medline

Guerreiro PS, Huang Y, Gysbers A, Cheng D, Gai WP, Outeiro TF, Halliday GM (2013) LRRK2 interactions with alpha-synuclein in Parkinson's disease brains and in cell models. J Mol Med (Berl) 91:513-522. CrossRef Medline

Henderson JL, Kormos BL, Hayward MM, Coffman KJ, Jasti J, Kurumbail RG, Wager TT, Verhoest PR, Noell GS, Chen Y, Needle E, Berger Z, Steyn SJ, Houle C, Hirst WD, Galatsis P (2015) Discovery and preclinical profiling of 3-[4-(morpholin-4-yl)-7H-pyrrolo[2,3-d]pyrimidin-5-yl]benzonitrile (PF-06447475), a highly potent, selective, brain penetrant, and in vivo active LRRK2 kinase inhibitor. J Med Chem 58:419-432. CrossRef Medline

Henry AG, Aghamohammadzadeh S, Samaroo H, Chen Y, Mou K, Needle E, Hirst WD (2015) Pathogenic LRRK2 mutations, through increased kinase activity, produce enlarged lysosomes with reduced degradative ca- 
pacity and increase ATP13A2 expression. Hum Mol Genet 24:6013-6028. CrossRef Medline

Ibáñez P, Bonnet AM, Débarges B, Lohmann E, Tison F, Pollak P, Agid Y, Dürr A, Brice A (2004) Causal relation between alpha-synuclein gene duplication and familial Parkinson's disease. Lancet 364:1169-1171. CrossRef Medline

Lee H, Melrose HL, Yue M, Pare JF, Farrer MJ, Smith Y (2010) Lrrk2 localization in the primate basal ganglia and thalamus: a light and electron microscopic analysis in monkeys. Exp Neurol 224:438-447. CrossRef Medline

Lee MK, Stirling W, Xu Y, Xu X, Qui D, Mandir AS, Dawson TM, Copeland NG, Jenkins NA, Price DL (2002) Human alpha-synuclein-harboring familial Parkinson's disease-linked Ala-53 $\rightarrow$ Thr mutation causes neurodegenerative disease with alpha-synuclein aggregation in transgenic mice. Proc Natl Acad Sci U S A 99:8968-8973. CrossRef Medline

Li X, Patel JC, Wang J, Avshalumov MV, Nicholson C, Buxbaum JD, Elder GA, Rice ME, Yue Z (2010) Enhanced striatal dopamine transmission and motor performance with LRRK2 overexpression in mice is eliminated by familial Parkinson's disease mutation G2019S. J Neurosci 30:1788-1797. CrossRef Medline

Lin X, Parisiadou L, Gu XL, Wang L, Shim H, Sun L, Xie C, Long CX, Yang WJ, Ding J, Chen ZZ, Gallant PE, Tao-Cheng JH, Rudow G, Troncoso JC, Liu Z, Li Z, Cai H (2009) Leucine-rich repeat kinase 2 regulates the progression of neuropathology induced by Parkinson's-disease-related mutant alpha-synuclein. Neuron 64:807-827. CrossRef Medline

Luk KC, Kehm V, Carroll J, Zhang B, O’Brien P, Trojanowski JQ, Lee VM (2012) Pathological alpha-synuclein transmission initiates Parkinsonlike neurodegeneration in nontransgenic mice. Science 338:949-953. CrossRef Medline

MacLeod D, Dowman J, Hammond R, Leete T, Inoue K, Abeliovich A (2006) The familial Parkinsonism gene LRRK2 regulates neurite process morphology. Neuron 52:587-593. CrossRef Medline

Martin I, Kim JW, Lee BD, Kang HC, Xu JC, Jia H, Stankowski J, Kim MS, Zhong J, Kumar M, Andrabi SA, Xiong Y, Dickson DW, Wszolek ZK, Pandey A, Dawson TM, Dawson VL (2104) Ribosomal protein s15 phosphorylation mediates LRRK2 neurodegeneration in Parkinson's disease. Cell 157:472-485.

Murphy DD, Rueter SM, Trojanowski JQ, Lee VM (2000) Synucleins are developmentally expressed, and alpha-synuclein regulates the size of the presynaptic vesicular pool in primary hippocampal neurons. J Neurosci 20:3214-3220. Medline

Orenstein SJ, Kuo SH, Tasset I, Arias E, Koga H, Fernandez-Carasa I, Cortes E, Honig LS, Dauer W, Consiglio A, Raya A, Sulzer D, Cuervo AM (2013) Interplay of LRRK2 with chaperone-mediated autophagy. Nat Neurosci 16:394-406. CrossRef Medline

Osterberg VR, Spinelli KJ, Weston LJ, Luk KC, Woltjer RL, Unni VK (2015) Progressive aggregation of alpha-synuclein and selective degeneration of Lewy inclusion-bearing neurons in a mouse model of parkinsonism. Cell Rep 10:1252-1260. CrossRef Medline

Paumier KL, Luk KC, Manfredsson FP, Kanaan NM, Lipton JW, Collier TJ, Steece-Collier K, Kemp CJ, Celano S, Schulz E, Sandoval IM, Fleming S, Dirr E, Polinski NK, Trojanowski JQ, Lee VM, Sortwell CE (2015) Intrastriatal injection of pre-formed mouse alpha-synuclein fibrils into rats triggers alpha-synuclein pathology and bilateral nigrostriatal degeneration. Neurobiol Dis 82:185-199. CrossRef Medline

Schreij AM, Chaineau M, Ruan W, Lin S, Barker PA, Fon EA, McPherson PS
(2015) LRRK2 localizes to endosomes and interacts with clathrin-light chains to limit Rac1 activation. EMBO Rep 16:79-86. CrossRef Medline Sepulveda B, Mesias R, LiX, Yue Z, Benson DL (2013) Short- and long-term effects of LRRK2 on axon and dendrite growth. PLoS One 8:e61986. CrossRef Medline

Sheng Z, Zhang S, Bustos D, Kleinheinz T, Le Pichon CE, Dominguez SL, Solanoy HO, Drummond J, Zhang X, Ding X, Cai F, Song Q, Li X, Yue Z, van der Brug MP, Burdick DJ, Gunzner-Toste J, Chen H, Liu X, Estrada AA, et al. (2012) Ser1292 autophosphorylation is an indicator of LRRK2 kinase activity and contributes to the cellular effects of PD mutations. Sci Transl Med 4:164ra161. Medline

Singleton AB, Farrer M, Johnson J, Singleton A, Hague S, Kachergus J, Hulihan M, Peuralinna T, Dutra A, Nussbaum R, Lincoln S, Crawley A, Hanson M, Maraganore D, Adler C, Cookson MR, Muenter M, Baptista M, Miller D, Blancato J, et al. (2003) alpha-Synuclein locus triplication causes Parkinson's disease. Science 302:841. CrossRef Medline

Singleton A, Myers A, Hardy J (2004) The law of mass action applied to neurodegenerative disease: a hypothesis concerning the etiology and pathogenesis of complex diseases. Hum Mol Genet 13:R123-R126. CrossRef Medline

Spillantini MG, Goedert M (2000) The alpha-synucleinopathies: Parkinson's disease, dementia with Lewy bodies, and multiple system atrophy. Ann N Y Acad Sci 920:16-27. CrossRef Medline

Steger M, Tonelli F, Ito G, Davies P, Trost M, Vetter M, Wachter S, Lorentzen E, Duddy G, Wilson S, Baptista MA, Fiske BK, Fell MJ, Morrow JA, Reith AD, Alessi DR, Mann M (2016) Phosphoproteomics reveals that Parkinson's disease kinase LRRK2 regulates a subset of Rab GTPases. Elife 5:e12813. Medline

Tran HT, Chung CH, Iba M, Zhang B, Trojanowski JQ, Luk KC, Lee VM (2014) Alpha-synuclein immunotherapy blocks uptake and templated propagation of misfolded alpha-synuclein and neurodegeneration. Cell Rep 7:2054-2065. CrossRef Medline

Volpicelli-Daley LA, Luk KC, Patel TP, Tanik SA, Riddle DM, Stieber A, Meaney DF, Trojanowski JQ, Lee VM (2011) Exogenous alphasynuclein fibrils induce Lewy body pathology leading to synaptic dysfunction and neuron death. Neuron 72:57-71. CrossRef Medline

Volpicelli-Daley LA, Luk KC, Lee VM (2014a) Addition of exogenous alpha-synuclein preformed fibrils to primary neuronal cultures to seed recruitment of endogenous alpha-synuclein to Lewy body and Lewy neurite-like aggregates. Nat Protoc 9:2135-2146. CrossRef Medline

Volpicelli-Daley LA, Gamble KL, Schultheiss CE, Riddle DM, West AB, Lee VM (2014b) Formation of alpha-synuclein Lewy neurite-like aggregates in axons impedes the transport of distinct endosomes. Mol Biol Cell 25:4010-4023. CrossRef Medline

Waxman EA, Giasson BI (2008) Specificity and regulation of casein kinasemediated phosphorylation of alpha-synuclein. J Neuropathol Exp Neurol 67:402-416. CrossRef Medline

Webber PJ, Smith AD, Sen S, Renfrow MB, Mobley JA, West AB (2011) Autophosphorylation in the leucine-rich repeat kinase 2 (LRRK2) GTPase domain modifies kinase and GTP-binding activities. J Mol Biol 412:94-110. CrossRef Medline

West AB, Cowell RM, Daher JP, Moehle MS, Hinkle KM, Melrose HL, Standaert DG, Volpicelli-Daley LA (2014) Differential LRRK2 expression in the cortex, striatum, and substantia nigra in transgenic and nontransgenic rodents. J Comp Neurol 522:2465-2480. CrossRef Medline 